\title{
Tightness Tests in Salt-Cavern Wells
}

\author{
P. Bérest ${ }^{1}$, B. Brouard ${ }^{2}$ et J.G. Durup 3 \\ 1 LMS et G.3S, École polytechnique, École des mines de Paris, École des ponts et chaussées, UMR 7649 CNRS - France \\ 2 LMS et Brouard Consulting, 37, rue du Petit-Musc, 75004 Paris - France \\ $3 \mathrm{Gaz}$ de France, 92-98, boulevard Victor-Hugo, 92110 Clichy - France \\ e-mail: berest@Ims.polytechnique.fr - brouard@Ims.polytechnique.fr - Gerard.Durup@GazdeFrance.com
}

\begin{abstract}
Résumé - Essais d'étanchéité dans les puits d'accès aux cavernes dans le sel - Des milliers de cavernes ont été creusées par dissolution dans des formations salifères ; elles sont utilisées pour stocker une grande variété de produits fluides, depuis l'air comprimé et l'hydrogène, jusqu'aux GPL, au gaz naturel et au pétrole brut. Ces cavernes doivent être étanches. Cet article présente les différents facteurs qui contribuent à la formation des fuites et à leur prévention : la distribution des pressions de fluide, l'environnement géologique, la qualité de la cimentation, l'architecture du puits. L'accident de Mont Belvieu est rappelé : il met en évidence l'importance des essais périodiques d'étanchéité. Nous présentons également les divers essais possibles, et nous distinguons les notions de fuite apparente, de fuite corrigée et de fuite réelle. Les facteurs contribuant à la fuite apparente sont examinés. Deux essais réels in situ sont décrits, utilisant respectivement du fioul et de l'azote comme fluide d'essai ; nous montrons qu'une analyse précise des résultats de l'essai permet d'évaluer correctement la fuite réelle en la distinguant des autres facteurs avec lesquels elle pourrait être confondue.
\end{abstract}

Mots-clés : cavernes dans le sel, étanchéité des puits, essais d'étanchéité, vérification de l'intégrité mécanique.

\begin{abstract}
Thousands of caverns have been leached out from salt formations. They are used for storing a variety of fluid products ranging from compressed air and hydrogen to LPG, natural gas and crude oil, which requires that the caverns be tight. The main factors in the onset of well leakage and its prevention are discussed: fluid pressure distribution, geological environment, cementing workmanship and well architecture. The Mont Belvieu accident is described to illustrate the importance of periodic cavern testing. Test methods are discussed; apparent, corrected and actual leaks are distinguished. Factors contributing to apparent leaks are described, as are two actual in situ tests that use fuel oil and nitrogen as test fluids. It is proven that a thorough test analysis allows good estimations of actual leaks.
\end{abstract}




\section{NOTATIONS}

\section{Latin Letters}

A geothermal gradient, $\mathrm{K} / \mathrm{m}$

C barometric coefficient

$g$ gravity acceleration, $\mathrm{m}^{2} / \mathrm{s}$

$h$ test-fluid/brine interface depth, $\mathrm{m}$

$H$ cavern depth, m

$K \quad$ intrinsic permeability of rock salt, $\mathrm{m}^{2}$

$k^{\text {th }} \quad$ thermal diffusivity of rock salt, $\mathrm{m}^{2} / \mathrm{s}$

$k^{\text {hyd }}$ hydraulic diffusivity of rock salt, $\mathrm{m}^{2} / \mathrm{s}$

$m$ gas mass, $\mathrm{kg}$

$P \quad$ gas pressure, $\mathrm{Pa}$

$P_{a} \quad$ annular pressure at well head, $\mathrm{Pa}$

$P_{b} \quad$ well-head brine pressure, $\mathrm{Pa}$

$P \quad$ well-head gas pressure, $\mathrm{Pa}$

$P_{i} \quad$ cavern brine pressure, $\mathrm{Pa}$

$P_{\text {int }} \quad$ nitrogen/brine interface pressure, $\mathrm{Pa}$

$P_{o} \quad$ halmostatic pressure, $\mathrm{Pa}$

$P_{\text {pore }}$ brine pore pressure, $\mathrm{Pa}$

$P_{t} \quad$ tubing pressure at well head, $\mathrm{Pa}$

$P_{\infty} \quad$ geostatic pressure, $\mathrm{Pa}$

$Q \quad$ nitrogen seepage rate, $\mathrm{m}^{3} / \mathrm{s}$

$Q_{a} \quad$ fuel-oil leak rate from the annular space, $\mathrm{m}^{3} / \mathrm{s}$

$Q_{b}$ brine flow rate through the casing shoe cross-section, $\mathrm{m}^{3} / \mathrm{s}$

$Q_{t} \quad$ brine leak rate from the central tubing, $\mathrm{m}^{3} / \mathrm{s}$

$R \quad$ cavern radius, $\mathrm{m}$

$r$ gas thermodynamic constant, $\mathrm{m}^{2} / \mathrm{s}^{2} / \mathrm{K}$

$S$ tubing cross-section area, $\mathrm{m}^{2}$

$T$ absolute temperature, $\mathrm{K}$

$T_{o} \quad$ ground-level absolute temperature, $\mathrm{K}$

$t^{\text {hyd }}$ characteristic time for hydraulic phenomena, $\mathrm{s}$

$t^{\text {th }} \quad$ characteristic time for thermal phenomena, $\mathrm{s}$

$V \quad$ cavern volume, $\mathrm{m}^{3}$

$V_{a} \quad$ leaked fuel volume, $\mathrm{m}^{3}$

$V_{g}$ gas volume, $\mathrm{m}^{3}$

$z$ depth, $m$.

\section{Greek Letters}

$\alpha \quad$ brine thermal-expansion coefficient, ${ }^{\circ} \mathrm{C}^{-1}$

$\beta \quad$ cavern compressibility factor, $\mathrm{Pa}^{-1}$

$\beta_{g} \quad$ gas compressibility factor, $\mathrm{Pa}^{-1}$

$\beta_{\text {pore }}$ salt pore compressibility factor, $\mathrm{Pa}^{-1}$

$\dot{\varepsilon} \quad$ cavern brine volume-change rate at constant pressure, $\mathrm{s}^{-1}$

$\dot{\varepsilon}_{\text {creep }}$ creep rate, $\mathrm{s}^{-1}$

$\dot{\varepsilon}_{\text {creep }}^{\mathrm{t}}$ transient creep rate, $\mathrm{s}^{-1}$

$\dot{\varepsilon}_{\text {dis }}$ relative volume-change rate due to dissolution, $\mathrm{s}^{-1}$ $\dot{\varepsilon}_{\text {perm }}$ relative brine seepage rate through cavern walls, $\mathrm{s}^{-1}$

$\dot{\varepsilon}_{\text {perm }}^{t}$ relative transient brine-seepage rate, $\mathrm{s}^{-1}$

$\dot{\varepsilon}_{\text {therm }}$ brine thermal expansion rate, $\mathrm{s}^{-1}$

$\eta \quad$ fluid dynamic viscosity, Pa.s

$\phi \quad$ porosity of rock salt

$\rho$ nitrogen density, $\mathrm{kg} / \mathrm{m}^{3}$

$\rho_{b} \quad$ brine density, $\mathrm{kg} / \mathrm{m}^{3}$

$\rho_{f} \quad$ fuel-oil density, $\mathrm{kg} / \mathrm{m}^{3}$

$\Sigma \quad$ annular space cross-section area, $\mathrm{m}^{2}$

$\theta_{o} \quad$ brine temperature at the end of leaching, ${ }^{\circ} \mathrm{C}$

$\theta_{R} \quad$ rock temperature at cavern depth, ${ }^{\circ} \mathrm{C}$

$\chi \quad$ ratio between gas density and gas pressure, $\mathrm{kg} / \mathrm{m}^{3} / \mathrm{Pa}$.

\section{INTRODUCTION}

Tightness is a fundamental prerequisite for many underground works where minimum product leakage is required. Natural gas is stored in depleted reservoirs or aquifers; LPG is stored in unlined galleries; and various hydrocarbons, from hydrogen and natural gas to crude oil, are stored in salt caverns. Nuclear waste are planned to be disposed of in deep geological formations. Salt caverns are also being considered as disposal sites for non-hazardous wastes (Veil et al., 1997) or tritiated waters (Bérest et al., 1997). Abandoned oilproduction wells must be sealed efficiently to avoid later circulation of fluids between layers that were separated by impervious layers in the natural configuration.

The aim of tightness has no absolute nature, but, rather, depends upon specific sensitivity of the environment and the economic context. Radionuclides become harmless after a certain period of time: provided the process is slow enough, penetration of nuclides into the rock mass adjacent to the disposal galleries may not impair storage safety. Air, natural gas, butane and propane are not poisonous from the perspective of underground-water protection: the leakage of sufficiently diluted natural gas into underground water has minor consequences for water quality. This would not apply to other products, such as crude oil.

From the viewpoint of ground-surface protection, the most significant risk is the accumulation of flamable gas near the surface. In this situation, gases that are heavier than air (propane, ethylene, propylene) are more dangerous than natural gas.

The economic viewpoint depends basically on the speed of the stock rotation and the nature of the products stored. For example, when storing compressed air to absorb daily excess electric power, a loss of $1 \%$ per day can be considered as reasonable. When storing oil for strategic reasons, (e.g., oil which will be used only during a crisis), a loss of $1 \%$ per year is a maximum value. 
In this paper, we will focus on the tightness of salt caverns used for storing hydrocarbons. The paper is divided in five parts. Part 1 explains the main factors contributing to the leakage (fluid pressure distribution, geological environment and well architecture), and a typical accident is described. The second part concerns tightness testing; a list of the main factors contributing to the misinterpretation of tightness tests is provided. In Part 3, this is applied to the "fuel-oil leak test" and an example of a very accurate in situ test is described. Part 4 proposes a mathematical theory for the "nitrogen leak test" and Part 5 describes an actual test aimed at validating this test method and the equations deduced in Part 4.

\section{FACTORS CONTRIBUTING TO THE PREVENTION OF LEAKAGE IN SALT CAVERNS}

\subsection{Introduction}

Salt caverns are deep cavities (from $300 \mathrm{~m}$ to $2000 \mathrm{~m}$ ) that are connected to the ground level through a cased and cemented well (see Fig. 1 and Fig. 2). One to several strings are set in the well to allow injection or withdrawal of fluids into or from the cavern.

The caverns are leached out from salt formations and range in volume from 5000 to $1000000 \mathrm{~m}^{3}$. They provide chemical plants with brine, or, more commonly, provide storage for large quantities of hydrocarbons. Obviously, tightness is a fundamental prerequisite for these cavities.

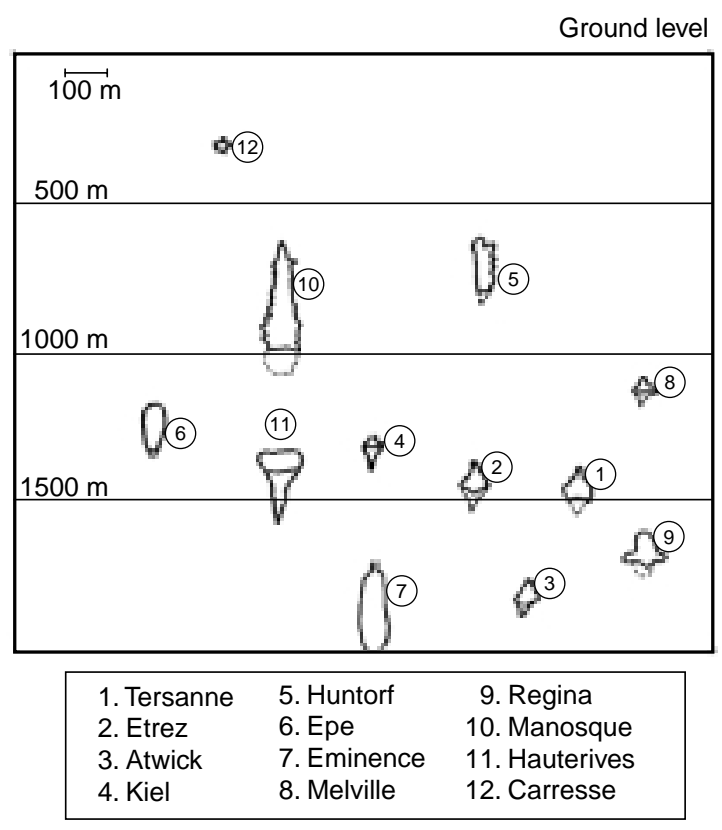

Figure 1

Vertical cross-sections of several salt-caverns.

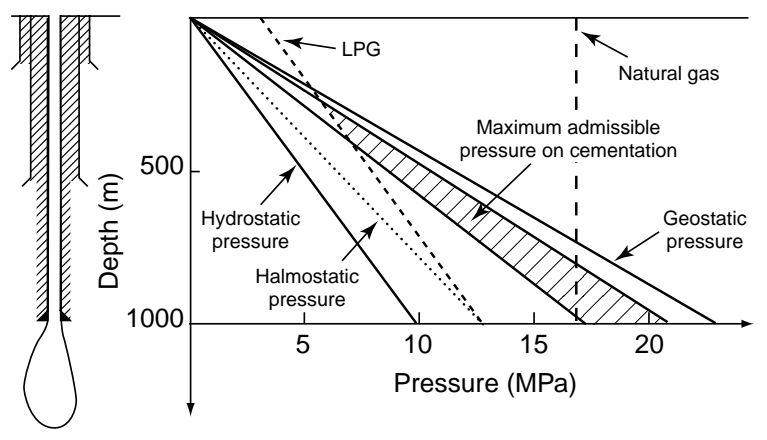

Figure 2

Underground pressure distribution.

From an engineering perspective, salt formations can be considered to be practically impermeable. Salt permeability can be as low as $K=10^{-22} \mathrm{~m}^{2}$; even in natural salt formations containing a fair amount of insoluble rocks (anhydrite or clay interbedded layers), average permeabilities of $K=10^{-20} \mathrm{~m}^{2}$ or $10^{-19} \mathrm{~m}^{2}$ are reported (Durup, 1994; Bérest et al., 2001). How low these figures are is proved by a simple calculation: for a $100000 \mathrm{~m}^{3}$ cavern containing brine with a pressure $10 \mathrm{MPa}$ larger than the natural brine pore pressure, a salt permeability of $K=10^{-20} \mathrm{~m}^{2}$ will generate a steady-state brine loss rate of $1 \mathrm{~m}^{3}$ per year (see Section 2.4.3). As will be seen, fluid seepage from the access well is probably much larger in many cases. In much the same way as for all pressure vessels, it is the "piping" that is the real problem i.e., the cemented borehole through which the hydrocarbons flow to and from the cavity.

\subsection{Main Factors in the Onset of Well Leakage}

Three factors contribute to the problem of leakage in wells: pressure distribution, geological environment and well architecture. These factors are discussed below.

\subsubsection{Pressure Distribution}

Fluid can only flow from an area of high pressure toward an area of lower pressure. Figure 2 shows pressure distribution as a function of depth.

Instead of the pressure at cavern-neck depth, it is convenient to speak of the associated "gradient" (or density) of a fluid column producing the same pressure at the same depth.

- The geostatic pressure ( $P_{\infty}$, gradient 2.2) is the natural stress expected in a sedimentary formation with a natural density of $2200 \mathrm{~kg} / \mathrm{m}^{3}$. Occasionally, anomalous stress can be encountered, especially in salt dome flanks, but $22 \mathrm{MPa}$ at a $1000 \mathrm{~m}$ depth is a standard value. This pressure must never be exceeded by any stored fluid, and there must be a safety margin; otherwise, there is a risk of fracturing or of drastic permeability increase (Durup, 1994; Rummel et al., 1996; Rokahr et al., 2000). 
- The hydrostatic pressure (gradient 1) is, in principle, the natural pressure of groundwater in water-bearing strata, although this figure is only an average value.

- The halmostatic pressure $\left(P_{o}\right.$, gradient 1.2) is the pressure in a saturated brine-filled well open at ground level.

- The maximum pressure, below which a cement-filled annular space will not leak significantly (gradient 1.8-2.0) is a purely empirical and site-specific notion: this pressure must not be exceeded at the casing shoe, where the cement is in direct contact with the stored product.

- The pressure of the stored product at cavern depth $\left(P_{i}\right)$ is equal to the halmostatic pressure in caverns storing liquid or liquified products. For natural-gas storage caverns, the maximum gas pressure is dictacted by the amount of leakage through the ciment-filled annular space, as explained in (4).

\subsubsection{Geological Formation}

If most of the rock formations through which the well crosses are impervious, the situation is, of course, extremely favourable. Salt domes are frequently surmounted by a very permeable zone (called caprock), where brine easily circulates between the pieces of rock left over from solution of the top of the salt dome: this situation requires special treatment (see the discussion on the Mont Belvieu case, below).

In contrast, soft-impervious formations can have a very favourable effect in that they naturally creep and tend to tighten around the well, improving the bond between the cement and the casing. For example, the salt layers in which the Tersanne natural gas facility is sited in France is overlain by $600 \mathrm{~m}$ of predominantly clayey ground. So-named "Cement Bond Logs" have revealed a significant improvement with the passage of time which is attributed to clay creep.

\subsubsection{Cementing Workmanship and Well Architecture}

Cementing in gas and oil wells is a "rough and ready" operation, but underground storage engineers work under a higher standard than is typical in ordinary oil-industry operations. This has led to many improvements in the techniques usually employed in oil drilling (e.g., use of admixtures, recementing, leak tests). The various logs kept allow the cement-steel or cement-rock quality bonding to be assessed (ATG Manual, 1985; Jordan, 1987; Kelly and Fleniken, 1999).

The architecture of the borehole is just as important, and errors are easier to identify. It is common knowledge that oil wells usually do not have only a single casing cemented into the ground; drilling proceeds in stages, and, in each stage, a casing is run and cemented into that level, with each casing having a smaller diameter than the preceding one. By the time the hole has reached its final depth, there are several concentric casings at the top, gradually decreasing in number lower down.
This obviously is beneficial for safety in a storage environment. We have seen that the positive pressure differential of products in a well increases toward the surface. It is equally true that, near the surface, any leakage starting at the junction between two casing lengths will be channeled in the cemented annular space between the inner casing and the outer casing. A leak can rise up the cemented annular space between the two casings, but it will come out at the surface at the hole collar, where it is easy to detect and treat.

The architecture of the well and the number and length of steel casings are generally selected with reference to the actual objectives of the drilling operations. These may be to shore up the hole through weak strata or to prevent communication between two aquifers at distinctly different pressures. Quite clearly, the objectives must also include leakage prevention, which may require a more complicated architecture to isolate a stratum that was not troublesome for the driller but which might later promote leakage through a single damaged casing. In particular, the last two cemented casings must be anchored in the salt formation or in an overlaying impermeable formation. As Thoms and Kiddoo (1998) state, "Once in the porous sand formations, the gas can readily migrate (...) This has happened in US Golf Coast wells (...) Thus two casing strings are now 'cemented' into the salt." In Texas, Rules 1995-97 of the Texas Railroad Commission, which is the authority in charge of oil matters in the area, make this design mandatory for wells completed later than 1993.

Gaz de France has opted for the most comprehensive solution by specifying double-tubing at all gas sites, with a central string inside the inner casing (Fig. 3). The annular space between them is plugged at the bottom and filled with fresh water. Any gas leak from the central string immediately results in a pressure build-up in the annular space, which is

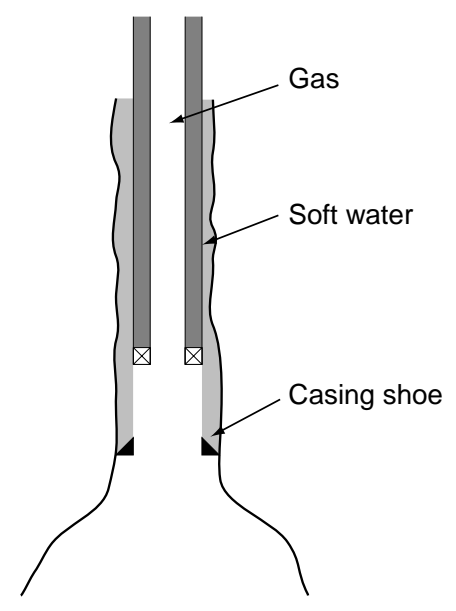

Figure 3

Water-filled annular space in $G D F$ natural gas storages. 
easily detected at ground level. The drawback of this solution is that it slightly reduces the effective diameter of the hole, as well as the rate at which products can be withdrawn. However, it has a very great advantage in that leaks can occur only at the tip of the cemented casing.

\subsection{Mont Belvieu Accident}

\subsubsection{The Accident}

The accident occurred in 1980 at Mont Belvieu, Texas, where a salt dome is used by a large number of companies and where several dozen cavities have been solution-mined. This site has the largest storage capacity for petrochemical products anywhere in the United States. A comprehensive description of this site and of the various problems it has experienced can be found in Ratigan (1991).

A drop in pressure was recorded on September 17, 1980, in one of the cavities containing liquefied petroleum gas. On October 3, gas (70\% ethane, 30\% propane) that had accumulated in the foundation of a house in the area exploded as a result of a spark from an electrical appliance. The cavity in which the pressure had dropped was then filled with brine; in the days that followed, gas appeared haphazardly around the area, and approximately 50 families had to be evacuated. Holes were drilled into the water tables above the salt to find and vent the gas. The company declined all responsibility outright, and an inquiry was opened by the Texas Railroad Commission.

In the absence of fully detailed information, we make a credible reconstruction of the accident based on a typical propane storage facility in a salt dome.

\subsubsection{Analysis of the Accident}

A salt dome is a geological structure in which an originally horizontal bed of salt has risen toward the surface by puncturing the overlying strata. When the dome reaches water-bearing layers, the top may dissolve, leaving a cap of insoluble rock surrounded by brine.

If the well casing is leaky (e.g., at a joint between two lengths or because of corrosion; the well "at fault" at Mont Belvieu dated from 1958), the products can escape toward the caprock. Leakage is faster when there is a high pressure differential between the product and the groundwater. The differential may be significant if the caprock lies much higher than the storage cavity.

Because of its low density, propane tends to rise to the surface, either through the cement along the outside of the casing or by dispersing in the overlying ground. This happens, for example, if it finds a sufficiently pervious waterbearing layer just below the surface. The gas can accumulate in building foundations or emerge at streams and similar lowlying ground - or come up through faults and joints, daylighting at the surface, several hundred meters from the well head.
Another lesson that can be drawn from the accident concerns the lifespan of wells. If the accident was caused by a leak in the well at the point at which the drop in pressure was recorded, we should remember that the well performed satisfactorily for 22 years and that the leak occurred suddenly.

\subsubsection{Measures Taken After the Accident}

As indicated above, following this accident, the Texas Railroad Commission decreed that future wells be equipped by two casing strings cemented into the salt. For the (hundreds of) existing involved caverns (as well as future caverns), it was decided that: "Each hydrocarbon (or gas) storage well shall be tested for integrity prior to being placed into service, at least once every five years, and after each workover that involves physical changes to any cemented casing string" (Railroad Commission of Texas, Rules $16+$ $\mathrm{AC} \S 3.95$ and 3.97).

A similar — but more severe- accident occurred recently (February 2001) in Hutchinson, Kansas. A complete picture of this accident is not yet available. Apparently, a natural-gas storage well became leaky, and natural gas migrated underground to a town $10 \mathrm{~km}$ from the well. Gas erupted, resulting in two deaths.

\section{SOME THEORETICAL ASPECTS OF TIGHTNESS TESTING}

\subsection{Introduction}

In general, when testing a pressure vessel, pressure is built up in the vessel to a level slightly above the maximum operating pressure. Leaks are detected through visual inspection or, more accurately, through records of pressure evolution. A dramatic pressure fall is a clear sign of poor tightness. A key question concerns the allowable rate of pressure decrease; it is usually fixed according to experience rather than through a more scientific understanding of the mechanisms of pressure decrease.

Selecting too high a test pressure is not recommended, even if such a choice provides better confidence in vessel tightness. For example, when storing natural gas in an underground facility, the maximum operating pressure tends to be close to the geostatic pressure, which is the maximum conceivable fluid pressure in an unlined underground opening. In this case, only a small margin is left for selecting a test pressure. When a vessel is decompressed after testing, the pressure decrease rate is also a matter of concern. This rate can be high, especially when a stiff test fluid is used; however, too fast a pressure release induces large tensile stresses and pore pressure gradients, which can be damaging to the rock formation or cemented wells. A moderate posttest pressure decrease rate is generally recommended. 
When available at a reasonable cost, a stiff, non-explosive and non-polluting test fluid is preferred so that the consequences of a leak during testing are benign. In addition, when a stiff fluid is used, a small leak causes a significant and easily detectable decrease in the pressure rate, providing a high sensitivity for the test system. The compressibility factor of a brine-filled salt cavern is approximately $\beta=$ $4 \cdot 10^{-4} \mathrm{MPa}^{-1}$ (Bérest et al., 1999; see also 2.6.2); in a $100000 \mathrm{~m}^{3}$ closed cavern, a $1 \mathrm{~m}^{3}$ fluid leak leads to a pressure drop of $2.5 \cdot 10^{-2} \mathrm{MPa}$, which is an easily detectable figure. Conversely, accurate testing of a salt cavern filled with natural gas is almost impossible. If the gas pressure is, say, $P=20 \mathrm{MPa}$, the compressibility of a gas-filled cavern is in the range $\beta_{g}=1 / \mathrm{P}=5 \cdot 10^{-2} \mathrm{MPa}^{-1}$, a figure which is too high to allow any accurate flow measurement of a leak. Testing a shallower, unlined gallery with air as the test fluid is easier, as the gallery is more accessible to measuring devices and its volume is smaller (Lindblöm et al., 1977).

A slightly different test procedure is possible in deep salt caverns. The cavern-plus-well system is similar to the ballplus-tube system used in a standard thermometer or barometer: compared to a huge cavity, the well appears as a very thin capillary, and tracking displacements of a fluidfluid interface in the well allows high sensitivity to cavernfluid volume changes to be obtained. When measuring interface displacement, an accuracy of $\delta h=15 \mathrm{~cm}$ for a $20 \mathrm{l} / \mathrm{m}$ well cross section is easily achieved, which means that brine movement of $Q_{b}=3 \cdot 10^{-2} \mathrm{~m}^{3}$ is detectable, even though the cavern volume can be $V=100000 \mathrm{~m}^{3}$.

\subsection{Tightness Tests in Salt Caverns}

A Mechanical Integry Test (MIT) is used to test cavern tightness. Two types of the MIT are currently used; these are described below (see Fig. 4).

- The Nitrogen Leak Test (NLT) consists of lowering a nitrogen column in the annular space below the last cemented casing. The central string is filled with brine, and a logging tool is used to measure the brine/nitrogen interface location. Two or three measurements, generally separated by $24 \mathrm{~h}$, are performed; an upward movement of the interface is deemed to indicate a nitrogen leak. Pressures are measured at ground level, and temperature logs are performed to allow precise calculation of nitrogen seepage.

- The Fuel-Oil Leak Test (FLT) is more popular in Europe than in the United States. It consists of lowering a fuel-oil (instead of nitrogen, as for the NLT) column in the annular space. During the test, attention is paid to the evolution of the brine and fuel-oil pressures as measured at the well head. A severe pressure-drop rate is a clear sign of poor tightness. In addition, the fuel-oil is withdrawn after the test and weighed, allowing comparison with the weight of the injected fuel-oil volume.

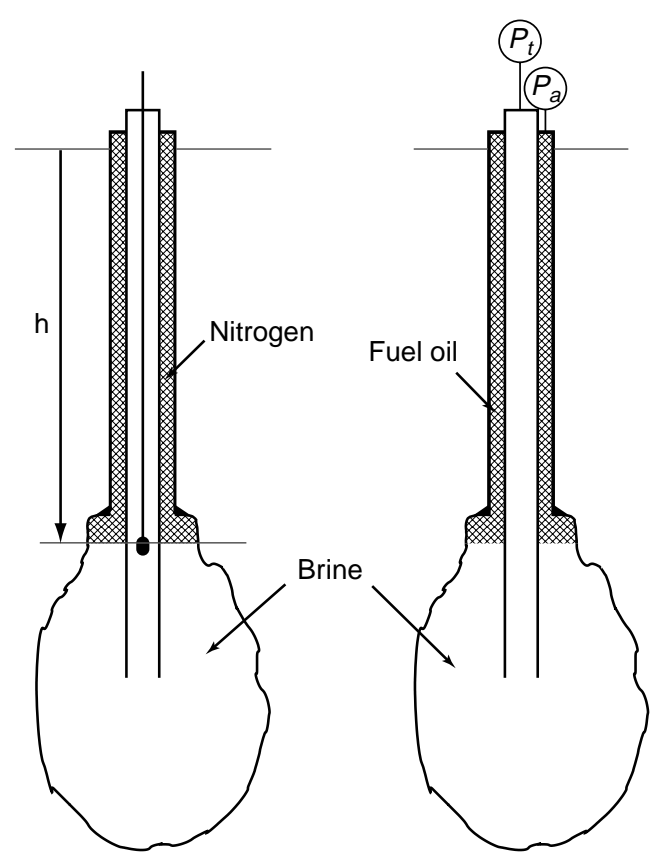

Figure 4

Nitrogen (left) versus Fuel-Oil (right) Leak Tests. (In the former, the nitrogen/brine interface is tracked through a logging tool. In the latter, tubing and annular pressures are continuously recorded at the well head during the test).

The FLT is generally used before the cavern is leached out; the NLT is used for full-size cavern testing. In the following, the accuracy and meaning of these two tests are discussed, two in situ experiments to validate mechanicalintegrity test methods are discussed, and modifications to enhance better interpretation are suggested.

There is relatively abundant available literature. Van Fossan (1983) and Van Fossan and Whelpy (1985) discuss both the legal and technical aspects of cavern-well testing and strongly support the NLT; they point out the significance of the Minimum Detectable Leakage Rate (MDLR) or the accuracy of the test method. In his 1987 paper, Heitman presents a set of case histories that illustrate several difficulties encountered when testing real caverns. Vrakas (1988) discusses the cavern-integrity program followed by the US Strategic Petroleum Reserve. Diamond (1989) and Diamond et al. (1993) propose the "water-brine interface method", in which soft water is injected in the well; any upward displacement of the water-brine interface results in a pressure drop at the well head, which is compared to the pressure evolution in a reference brine-filled well. Brasier (1990) proposes a similar method. In the following, we propose a brine-fuel oil interface method that is based on the same idea. Thiel (1993) suggests precision methods for calipering the interface location area cross-section, an 
essential issue for nitrogen-method accuracy. The Solution Mining Research Institute (SMRI), an association of companies and consultants involved with salt caverns, has promoted research in the MIT field, including a remarkable work by Crotogino (1995), who proposes standards for the MDLR and MALR (maximum allowable leak rate). In 1998, the SMRI organized a technical class dedicated to Mechanical Integrity Testing of Brine Production and Storage Caverns to provide a comprehensive assessment of the state of the art.

\subsection{Tracking the Actual Leak: Apparent, Corrected and Actual Leaks}

Testing the tightness of an underground storage facility involves recording the decrease of well-head pressure and/or tracking a fluid/fluid interface in the well. The pressuredecrease rate or interface velocity can then be converted into a "fluid leak rate" through simple calculations. In fact, several different mechanisms, of which the actual leak is only one, combine to produce a fluid-pressure decrease or an interface displacement. These mechanisms must be identified and quantified in each case. They include fluid leaks as well as rock-mass creep, heat transfer, brine thermodynamical equilibrium displacement, etc.

One must distinguish between:

- the "apparent" leak, bluntly deduced from the observed pressure decrease or interface displacement;

- the "corrected" leak, obtained when taking into account well-known and easily quantifiable mechanisms contributing to the apparent leak (for example, changes in fluid temperatures); and

- the "actual" leak, which, in some cases, can differ greatly from the apparent leak (and even from the corrected leak).

\subsection{Phenomena Existing Prior to Testing}

In most cases, for all practical purposes, a steel pressure vessel can be assumed to be in an equilibrium state before a pressure build-up test is performed. The same cannot be said of an underground cavern. A few examples will illustrate this statement.

Equilibrium is expected to have been reached when both the cavern and the well are filled with saturated brine and the well head has been open to the atmosphere for several weeks. In fact, common experience proves that, even several years after leaching has been completed, an opened cavern expels a significant flow of brine, from a few litres to several cubic meters per day (see, for example, Hugout, 1988, or Brouard, 1998). This brine outflow can be attributed to two main mechanisms: cavern creep and brine warming.

Later on, we adopt the following convention: any physical phenomenon as steady-state creep, thermal expansion (resp. brine permeation, additional dissolution, transient creep following a rapid pressure build-up) leading to a pressure build-up (resp. pressure decrease) in a closed cavern will be described by a positive (resp. negative) relative volume change rate (resp. $\dot{\varepsilon}>0$ or $\dot{\varepsilon}<0$ ).

\subsubsection{Cavern Creep}

First, mechanical equilibrium is not reached at cavern depth in a cavity opened to the atmosphere. Rock salt behaves as a fluid -i.e., it flows even under small deviatoric stresses; creep rate is a highly non-linear function of applied stress and temperature. For a salt cavern, these rheological properties induce a slow perennial loss of cavern volume, ultimately leading to complete cavern closure. In an opened cavern, brine pressure $\left(P_{i}\right)$ at cavern depth $(H)$ results from the weight of the brine column in the well (Fig. 2):

$$
P_{o}(\mathrm{MPa})=0.012 H(\mathrm{~m})
$$

(This pressure has been termed "halmostatic"), whereas geostatic pressure $\left(P_{\infty}\right)$ results from the weight of the overlying ground (Fig. 2 ):

$$
P_{\infty}(\mathrm{MPa})=0.022 H(\mathrm{~m})
$$

For example, in a $1000 \mathrm{~m}$ deep cavern, the $P_{\infty}-P_{i}$ difference is $10 \mathrm{MPa}$; this difference is the driving force for salt creep and cavern shrinkage. At such a depth, steady-state volume loss rate $\left(\dot{\varepsilon}_{\text {creep }}>0\right)$ of a cavern is of the order of $\left(\dot{\varepsilon}_{\text {creep }}=3 \cdot 10^{-4}\right.$ per year. (In other words, the annual loss of volume is $30 \mathrm{~m}^{3}$ per year in a $100000 \mathrm{~m}^{3}$ opened cavern.) Higher stresses and temperature in a deeper cavern will lead to a volume loss rate of the order of $\left(\dot{\varepsilon}_{\text {creep }}=3 \cdot 10^{-2}\right.$ per year at a depth of $2000 \mathrm{~m}$. (These figures are indicative and can vary, to a large extent, from one site to another; see Brouard and Bérest, 1998). However, when performing a leak test, a significant increase in cavern pressure is implied, followed by a reduction of the $P_{\infty}-P_{i}$ difference; the steady-state creep rate during the test (transient creep will be dealt later) will be much smaller than when the cavern was opened. The same cannot be said of brine thermal expansion, which is not influenced by cavern pressure.

\subsubsection{Brine Warming}

The natural temperature of rock increases with depth; typically, $\theta_{R}=45^{\circ} \mathrm{C}$ at a depth of $1000 \mathrm{~m}$. Soft water injected in the cavern during the leaching phase is pumped out from shallow aquifers; its temperature can be $12-15{ }^{\circ} \mathrm{C}$. Brine warms up in the cavern, but, because the withdrawal flow rate is relatively high $\left(100 \mathrm{~m}^{3} / \mathrm{h}\right)$, brine does not have enough time to reach thermal equilibrium with the rock mass during the leaching phase. When leaching-out is completed, a substantial temperature gap, $\theta_{R}-\theta_{o}$, is still present between the rock mass and the cavern brine. 
When the cavern remains idle, the brine warms up slowly; its temperature is roughly homogeneous throughout the cavern, as it is stirred by natural convection. Heat transfer then is governed by thermal conduction from the rock mass to the cavern. Let $V$ be the volume of the cavern, whose shape is assumed to be roughly spherical; then, the characteristic time after which, say, $75 \%$ of the initial temperature gap is resorbed, is $t^{\text {th }}=V^{2 / 3} /\left(4 k^{\text {th }}\right)$, where $k^{\text {th }}$ is the rock thermal diffusivity $\left(k^{\text {th }}=100 \mathrm{~m}^{2} /\right.$ year). For a cavern with $V=8000 \mathrm{~m}^{3}, t^{\text {th }}=1$ year. Brine warms considerably slower in a large cavern - for example, $t^{\text {th }}=16$ years when $V=500000 \mathrm{~m}^{3}$. Brine warming leads to thermal expansion; the average brine thermal-expansion rate is $\dot{\varepsilon}_{\text {therm }}=0.75 \alpha$ $\left(\theta_{R}-\theta_{o}\right) / t^{\text {th }}>0$, where $\alpha=4.4 \cdot 10^{-4}{ }^{\circ} \mathrm{C}^{-1}$ is the brine thermal expansion coefficient, and $\theta_{R}-\theta_{o} \approx 30^{\circ} \mathrm{C}$ is the initial temperature gap, or $\dot{\varepsilon}_{\text {therm }}=10^{-2}$ per year in an $8000 \mathrm{~m}^{3}$ cavern $\left(\dot{\varepsilon}_{\text {therm }}=0.6 \cdot 10^{-3}\right.$ per year in a $500000 \mathrm{~m}^{3}$ cavern $)$. These figures are merely indicative; more precise predictions can be reached through numerical computation.

Steady-state creep and thermal expansion result in pressure build-up in a closed cavern, and, as such, can partly conceal a casing leak. Brine transport to the rock mass has the opposite effect.

\subsubsection{Salt Permeability}

As stated above, the intrinsic permeability of salt is exceedingly low, $K=10^{-22} \mathrm{~m}^{2}$ to $K=10^{-19} \mathrm{~m}^{2}$. Durup (1994) performed permeability tests in a well at the Etrez site and proved that the Darcy law holds and that pore pressure in this formation is close to halmostatic pressure - no brine flow takes place when the cavern is opened. During a tightness test, brine pressure is significantly larger than pore pressure, resulting in a brine leak to the formation. In a spherical cavern of radius $R$, the steady-state relative loss of volume is:

$$
\dot{\varepsilon}_{\text {perm }}=-\frac{3 K\left(P_{i}-P_{\text {pore }}\right)}{\eta R^{2}}<0
$$

where $\eta=1.2 \cdot 10^{-3} \mathrm{~Pa} \cdot \mathrm{s}$ is the viscosity of brine, $P_{i}$ is the cavern brine pressure, and $P_{\text {pore }}$ is the pore pressure. If we assume, for example, $P_{i}-P_{\text {pore }}=10 \mathrm{MPa}$ and $R=30 \mathrm{~m}$ $\left(V=100000 \mathrm{~m}^{3}\right)$, then $\dot{\varepsilon}_{\text {perm }}=-10^{-5}$ per year when $K=10^{-20} \mathrm{~m}^{2}$.

\subsubsection{Well Temperature}

If the well diameter is relatively small (a few decimetres), the thermal equilibrium between the rock mass and well fluid is reached much faster than in the cavern itself. However, if the well has been active just before the test (i.e., large amounts of fluids have circulated in the well for a period lasting several weeks or months before the test), the rock temperature in the vicinity of the well can be significantly different from the natural geothermal temperature. When the well is kept idle, the natural temperature will slowly be restored, but this process can be long and will lead to significant evolutions of well-fluid temperature until thermal equilibrium is reached.

\subsection{Transient Phenomena Triggered by the Test}

Several preexisting phenomena (e.g., cavern steady-state creep and brine thermal expansion) lead to cavern pressure build-up, concealing actual leaks and making the apparent leak smaller than the actual leak. Conversely, the rapid pressure build-up performed at the beginning of a tightness test triggers transient phenomena, which, according to the Le Chatelier principle, tend to restore the preexisting pressure and make the apparent leak larger than the actual leak. Three such phenomena are described below.

\subsubsection{Transient Creep}

Pressure build-up at the beginning of the test reduces the difference between the overburden pressure $\left(P_{\infty}\right)$ and the cavity pressure $\left(P_{i}\right)$, ultimately leading to a smaller steadystate volume creep loss rate. However, during a transient period (typically, 2 weeks long), the cavity responds to the pressure build-up by increasing the cavern volume $\left(\dot{\varepsilon}_{\text {creep }}^{t}<0\right)$. This phenomenon is observed in the laboratory during uniaxial multi-step creep tests and is referred to as "inverse creep" (Van Sambeek, 1993; Hunsche, 1991; Munson et al., 1996; Charpentier et al., 1999). The effects of transient inverse creep in a cavern have been described by Hugout (1988) (see Fig. 5)

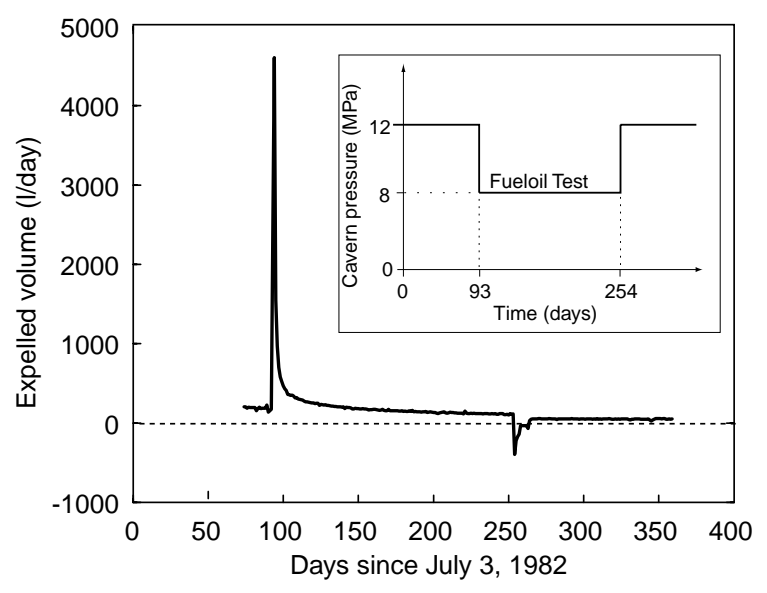

Figure 5

Transient creep and additional dissolution effects as observed during a test (after Hugout, 1988). (A pressure drop (day 93) induces a large transient cavern-shrinkage rate, and a rapid pressure build-up (day 254) induces a transient cavern expansion). 
In this paragraph, the origin of time is the day when cavern leaching is completed. From day 93 to day 254, the annular space is filled with fuel oil with a density of $\rho_{f}=850 \mathrm{~kg} \cdot \mathrm{m}^{-3}$, which results in low cavity pressure and large cavern creep rate. At day 254, the cavern is shut in, and brine is poured in the central tubing, resulting in a higher cavity pressure and, eventually, in a smaller steady-state creep rate. However, for several days, transient inverse creep results in an increase in cavern volume. After approximately 12 days (Remizov et al., 2000, observed a shorter transient period during an in situ test.), this transient effect vanishes, the accumulated apparent increase of cavity volume is $\dot{\varepsilon}_{\text {creep }}^{t}+\varepsilon_{\text {diss }}=$ several $-10^{-4}$, and a lower steady-state cavern creep rate is observed (the cavern shrinks). This transient mechanical phenomenon combines with additional dissolution.

\subsubsection{Additional Dissolution}

Brine saturation, or the amount of salt that can be dissolved in a given mass of soft water, is an increasing function of fluid pressure. When pressure builds up at the beginning of the test, additional dissolution takes place to reach the new equilibrium saturation. Because the brine volume is smaller than the sum of the volumes of its components (salt and water), dissolution leads to a net increase in cavern volume. Because dissolution is governed by diffusion through the brine body, the new equilibrium is not reached immediately. The kinetics of this phenomenon are not easy to describe, as its effects are intermingled with those of transient creep.

\subsubsection{Transient Permeation}

We computed the relative brine-volume loss rate, $\dot{\varepsilon}_{\text {perm }}$, when steady-state seepage from the cavern is reached. This steadystate regime is preceded by a transient period during which the brine flow rate is much higher. For example, in a spherical cavern of radius $R$,

$$
\dot{\varepsilon}_{\text {perm }}^{t}=\dot{\varepsilon}_{\text {perm }} \frac{R}{\sqrt{\pi k_{\mathrm{hyd}} t}}
$$

where $k_{\text {hyd }}$ is the hydraulic diffusivity, $K=k_{\text {hyd }} \phi \beta_{\text {pore }} \eta ; \phi$ is the porosity of salt, and $\left(\phi=10^{-2}\right), \beta_{\text {pore }}$ is the pore compressibility $\left(\beta_{\text {pore }}=4 \cdot 10^{-10} \mathrm{~Pa}^{-1}\right)$. The characteristic time of the transient phase, $t^{\text {hyd }}=R^{2} /(\pi \kappa)$ in a $V=100000 \mathrm{~m}^{3}$ cavern, varies from 5 years (when $K=10^{-21} \mathrm{~m}^{2}$ ) to 2 weeks (when $K=10^{-19} \mathrm{~m}^{2}$ ).

\subsection{External Effects}

\subsubsection{Definition}

In the following, "external effects" are defined as the set of mechanisms described above, apart from the actual fluid leak, which tend to modify cavern or brine volume and contribute to the apparent leak:

$$
\dot{\varepsilon}=\dot{\varepsilon}_{\text {creep }}+\dot{\varepsilon}_{\text {therm }}+\dot{\varepsilon}_{\text {perm }}+\dot{\varepsilon}_{\text {dis }}+\dot{\varepsilon}_{\text {creep }}^{t}+\dot{\varepsilon}_{\text {perm }}^{t}
$$

where $\dot{\varepsilon}$ is the relative cavern brine volume-change rate (at constant pressure).

The relative importance of these various phenomena depends upon cavern size, depth, age and time (i.e., the instant the observation is made).

- In an old, deep cavern, $\dot{\varepsilon}=\dot{\varepsilon}_{\text {creep }}=>0$ is the largest term in many cases.

- In a young, shallow cavern, $\dot{\varepsilon}=\dot{\varepsilon}_{\text {therm }}=>0$ is the largest term.

- When observations are made immediately after the pressure build-up, $\dot{\varepsilon}=\dot{\varepsilon}_{\text {dis }}+\dot{\varepsilon}_{\text {therm }}+\dot{\varepsilon}_{\text {creep }}^{t}<0$ is the most significant term.

These conclusions hold for a cavity. For a small-diameter well, the thermal equilibrium is reached relatively rapidly, and $\dot{\varepsilon}_{\text {therm }}$ is negligible, as is $\dot{\varepsilon}_{\text {perm }}^{t}$.

It must be remembered that, during a nitrogen leak test, the expected nitrogen leak rate is of the order of $Q=$ $0.5 \mathrm{~m}^{3} /$ day. The importance of "external factors" is seen clearly by considering the thermal expansion effects, which amount to $V \dot{\varepsilon}=0.8 \mathrm{~m}^{3} /$ day in a cavern with $V=500000 \mathrm{~m}^{3}$.

\subsubsection{Cavern Compressibility}

Both the cavity and the cavity brine are compressible bodies: when the cavern brine pressure $\left(\dot{P}_{i}\right)$ changes, it results in an inflow or outflow of brine from the cavity to the well:

$$
\dot{\varepsilon}_{\text {comp }}=-\beta \dot{P}_{i}
$$

where $\beta$ is the cavern compressibility factor, typically $\beta=4 \cdot 10^{-10} \mathrm{~Pa}^{-1}$. However, the compressibility factor can increase drastically when the cavern contains gas pockets. A comprehensive discussion of this can be found in Bérest $e t$ al. (1999). Cavern compressibility combines with external effects; brine flow that is expelled from the cavern and that enters the well can be expressed as:

$$
Q_{b}=\left(\dot{\varepsilon}-\beta \dot{P}_{i}\right) V
$$

\section{THE FUEL-OIL TEST}

\subsection{Introduction}

The Fuel-oil Leak Test is simpler than the Nitrogen Leak Test, but it is a little less demanding from the perspective of checking tightness and has several advantages:

- For a given cavern test pressure, fuel-oil, which is heavier than nitrogen, involves lower well-head pressures.

- Pressure evolution is recorded at the well head. 
- No logging tool is required, and the recording can be performed continuously for the duration of the test.

- Gauging the fuel-oil weight before and after the test can be performed easily.

We will see in Paragraph 3.3 that discriminating between the actual leak (i.e., from the well to the formation) and the apparent leak (i.e., from the cavern to the salt formation) can be accomplished through a simple — but accurate - method. The only weakness of this test lays in the high viscosity of fuel oil (when compared to the viscosity of nitrogen), which impairs test accuracy. (In comparable conditions, a gas leak is much larger than a liquid leak).

In fact, fuel-oil and nitrogen leaks through a porous brinesaturated formation are not easy to compare: fluid flow is governed by such phenomena as capillary pressure and twophase flow in a porous medium, which are difficult to quantify precisely. When interpreting a tightness test, volume loss is of primary interest. Assuming Darcy flow (a somewhat arguable hypothesis), the seepage volume flow rate can be written as:

$$
\underline{Q}=-\frac{K}{\eta} \underline{\operatorname{grad} P}
$$

where $K$ is the intrinsic permeability, $\eta$ is the fluid dynamic viscosity, and volumetric flow is inversely proportional to fluid viscosity. For nitrogen, $\eta=2 \cdot 10^{-5} \mathrm{~Pa} \cdot \mathrm{s}$; for brine, $\eta=1.2 \cdot 10^{-3} \mathrm{~Pa} \cdot \mathrm{s}$; for LPG, $\eta=1.3 \cdot 10^{-4} \mathrm{~Pa} \cdot \mathrm{s}$; and for crude oil, $\eta=10^{-2} \mathrm{~Pa} \cdot \mathrm{s}$. In fact, flow may occur through channels (e.g., at the steel-cement or cement-rock interfaces). Flow rates then depend on such factors as flow regime (Reynolds number), geometry of flow path, etc. A tentative analysis can be found in Goin (1983).

When the mass flow rate is considered, the figures change: Crotogino (1995) suggests that, when comparing the flow rates of viscous fluids to the flow rate of nitrogen for similar pressure conditions, the mass flow rate must be divided by 2 (LPG), 3 (gas oil) or 10 (crude oil). (Cavern temperature and pressure are $300{ }^{\circ} \mathrm{K}$ and $17 \mathrm{MPa}$.) Clearly, this issue is open to discussion.

\subsection{Field Test}

During a field test, the well is equipped with a central tubing of length a little longer than the length of the last cemented casing. A small fuel-oil column is set in the central tubing, and the annular space is filled with fuel oil. The fuel-oil/brine interface in the annular space is located below the last casing shoe (Fig. 4). Pressure is built up to the test figure; then, the pressure evolution at the well head is recorded versus time.

Such a test has been performed on the Ez53 cavern, a brine-filled cavern at the Etrez site operated by Gaz de France. The cavern depth is $950 \mathrm{~m}$ (Fig. 6), and its volume is $V=7500 \mathrm{~m}^{3} \pm 500 \mathrm{~m}^{3}$. The well was tested in 1997-1998,

\section{Perspective isometrique}

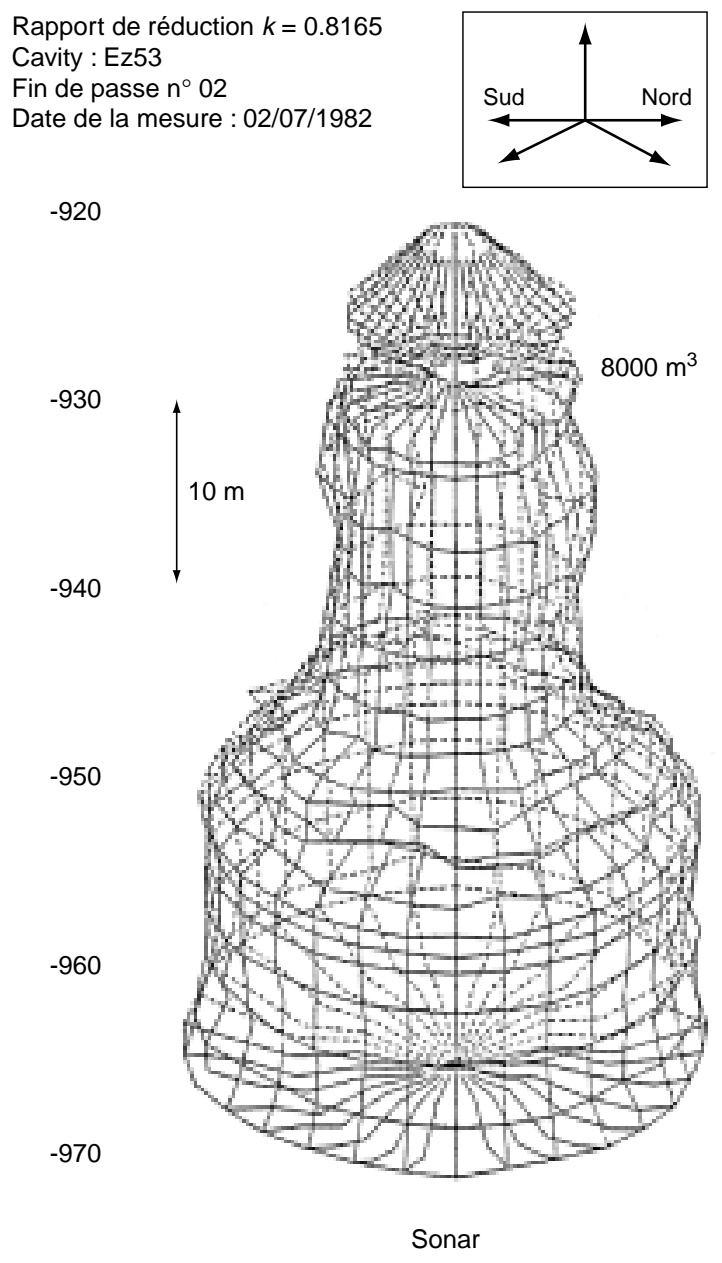

Figure 6

The Ez53 cavern.

16 years after it was leached out; the brine thermal expansion was then negligible $\left(\dot{\varepsilon}_{\text {therm }}=0\right)$, see Paragraph 5.1, and the asmeasured opened-cavern creep was small $\left(\dot{\varepsilon}_{\text {creep }}=3 \cdot 10^{-4}\right.$ per year, or $\dot{V}=2.2 \mathrm{~m}^{3}$ per year). The fuel-oil leak test was part of a test program, described in Bérest et al. (2001), which lasted 500 days. Such a long duration permits extremely accurate measurements to be made: transient external factors play no role, $\left(\dot{\varepsilon}_{\text {perm }}^{t}=\dot{\varepsilon}_{\text {dis }}=\dot{\varepsilon}_{\text {creep }}^{t}=0\right)$.

In the following, the origin of time (day 1) is March 27, 1997. The completed well includes a $24.45 \mathrm{~cm}\left(9^{5 / 8}\right.$ in) cemented casing and a $17.78 \mathrm{~cm}$ (7 in) string.

Before the test, on March 20, 1997 (day 7), a fuel-oil column was lowered in the $17.78 \mathrm{~cm} \cdot 24.45 \mathrm{~cm} \mathrm{(7} \mathrm{in.} 9^{5 / 8}$ in) annular space, to a depth of $h=864.5 \mathrm{~m}$, where the horizontal cross-section area is $\Sigma=5.7 \mathrm{l} / \mathrm{m}$ (Fig. 7).

On November 20 (day 238), the system was completed by lowering a smaller fuel-oil column into the $17.78 \mathrm{~cm}$ (7 in) 


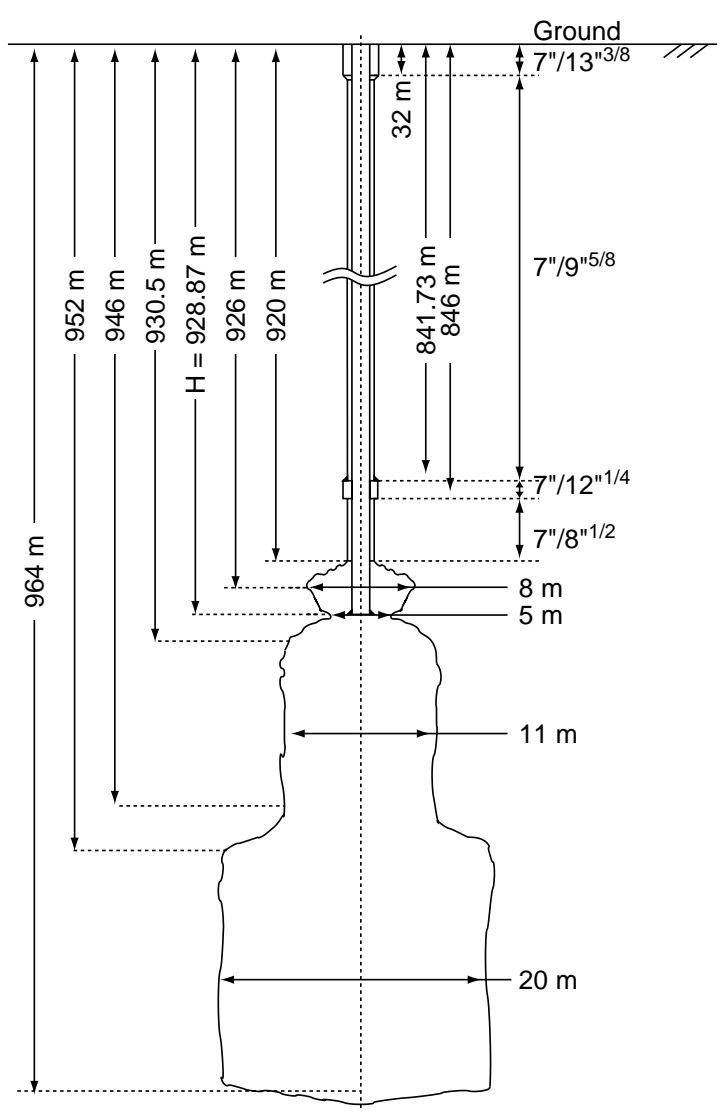

Figure 7

Ez53 completion during the fuel-oil leak test.

central tubing, to an approximate depth of $9.5 \mathrm{~m}$. (It would have been better to have set this second column before the test.) The horizontal cross-section of the tubing is constant and approximately equal to $S=21.1 \mathrm{l} / \mathrm{m}$. The monitoring system was then completed. However, following the appearance of leaks in days 293 to 315, additional fuel-oil was injected (on March 10, 1998; day 348) into the central tubing, which lowered the fuel-oil/brine interface to an approximate depth of $43 \mathrm{~m}$. Well-head pressures were measured through Rosemount pressure gauges (model $3051 \mathrm{CG}$ ) with a resolution of $\pm 5 \mathrm{hPa}$ and a maximum drift of $\pm 3 \mathrm{hPa}$ per year. At the beginning of the test, the wellhead annular pressure (the fuel-oil density is $\rho_{f}=850 \mathrm{~kg} / \mathrm{m}^{3}$ ) is larger than the well-head tubing pressure (the brine density is $\left.\rho_{b}=1200 \mathrm{~kg} / \mathrm{m}^{3}\right)$ by $g\left(\rho_{b}-\rho_{f}\right) h=9.8 \cdot(1200-850) \cdot 864=$ $3 \mathrm{MPa}$.

\subsection{Relation Between Well-Head Pressures and Leak Rates}

It is essential to be able to distinguish between (1) leaks through the well-head, (2) fuel-oil leaks through the cemented casing, and (3) brine seepage through the cavern walls or other external effects. Here we are interested primarily in evaluating (2). In fact, the measurement system allows easy comparison of the various types of leaks (Fig. 8). Such a system was first proposed by Diamond (1989) for the case of a water-brine interface.

Let $V \dot{\varepsilon}_{\text {creep }}$ be the cavern shrinkage rate due to salt creep and $V \dot{\varepsilon}_{\text {creep }}$ be the brine outflow rate from the cavern to the rock mass through the cavern walls. $Q_{a}$ is the fuel-oil leak rate through the casing (or casing shoe), $Q_{t}$ is the fuel-oil leak rate through the well head, and $Q_{b}$ is the (upward) brine flow from the cavern to the well. In the absence of any leak, $Q_{b}=$ $Q_{a}+Q_{t}=0$. Brine seepage ( $V \dot{\varepsilon}_{\text {creep }}$ ) from the cavern and cavern shrinkage ( $V \dot{\varepsilon}_{\text {creep }}$ ) generate the same pressure drop rate or pressure build-up $\left(\dot{P}_{i}\right)$ in the cavern as well as in both the annular space $\left(\dot{P}_{a}\right)$ and the central tubing $\left(\dot{P}_{t}\right)$ at the well head. Let $Q_{b}=0$ and $\dot{\varepsilon}=\dot{\varepsilon}_{\text {creep }}+\dot{\varepsilon}_{\text {perm }}$ in (7):

$$
\dot{P}_{i}=\dot{P}_{a}=\dot{P}_{t}=\left(\dot{\varepsilon}_{\text {creep }}+\dot{\varepsilon}_{\text {perm }}\right) / \beta
$$

where $\beta$ is the cavern compressibility factor, as defined above. Brouard (1998) has measured compressibility of the Ez53 cavern as approximately $\beta V \approx 3 \mathrm{~m}^{3} \cdot \mathrm{MPa}^{-1}$; in other words, brine seepage of $3 \mathrm{l} / \mathrm{day}$ will lead to a pressure drop rate of $1 \mathrm{kPa} /$ day.

In the example provided in Figure 9, during days 112 to 146, the average pressure drop rate is $\dot{P}_{a}=-869.70 \mathrm{~Pa} /$ day in the annular space and $\dot{P}_{t}=-869.85 \mathrm{~Pa}$ /day in the central tubing; the two curves (pressure versus time) are then almost perfectly parallel, proving that seepage takes place in the cavern itself - in sharp contrast to what happens in the case of a fuel-oil leak. During this period, brine seepage from the cavern (or, more precisely, the difference $V\left(\left|\dot{\varepsilon}_{\text {perm }}\right|-\left|\dot{\varepsilon}_{\text {creep }}\right|\right)$ between brine seepage and cavern creep) is $\beta V \dot{P}_{i}=3 \cdot 0.87=$ $2.6 \mathrm{l} /$ day. Note that very small oscillations (period $\approx 12 \mathrm{~h}$, amplitude $\approx 5 \mathrm{hPa}$ ) can be observed on the two curves. These can be related to terrestrial tidal waves and ground-level temperature changes. (The cavern volume changes every $12 \mathrm{~h}$ and $25 \mathrm{~min}$ by approximately $10^{-7}$ due to tidal waves. With the cavern compressibility factor being $\beta=4 \cdot 10^{-4} \mathrm{MPa}^{-1}$, tidal waves are responsible for pressure fluctuations of approximately $250 \mathrm{~Pa}$, a figure consistent with the observed oscillations. Furthermore, the daily atmospheric temperature variations, which propagate a few meters down the metallic tubes, are able to warm up - or cool down — the well brine once daily, leading to lower brine density and larger brine volume in the upper part of the well, both of which leading to a small pressure build-up).

A fuel-oil leak $\left(Q_{t}\right)$ from the central tubing through the well head will produce a similar pressure drop both in the cavern and in the annular space -i.e., $\dot{P}_{i}=\dot{P}_{a}=-Q_{t} /(\beta V)$. However, brine density $\left(\rho_{b}=1200 \mathrm{~kg} / \mathrm{m}^{3}\right)$ is significantly 

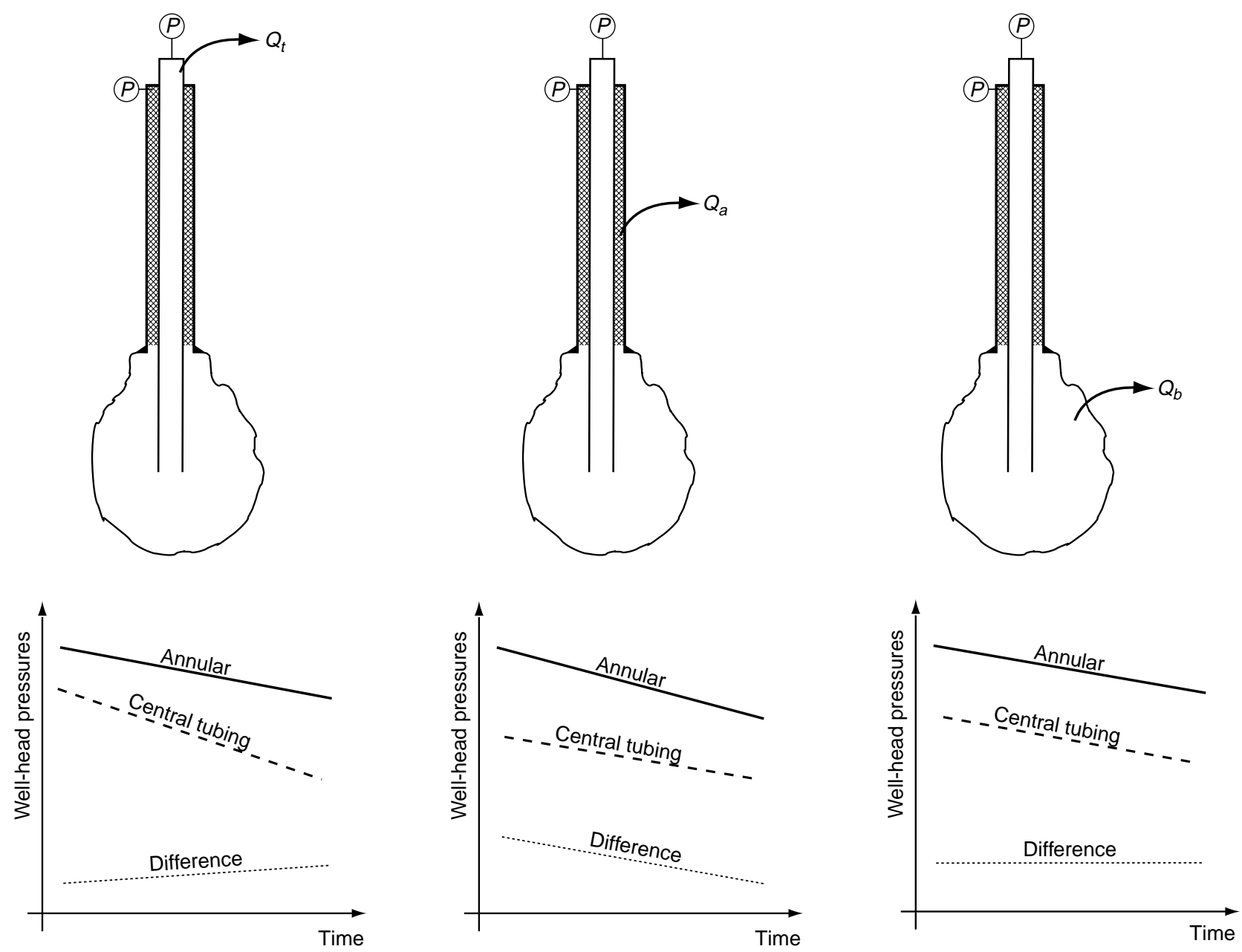

Figure 8

Various type of leaks and their effects on well pressure.

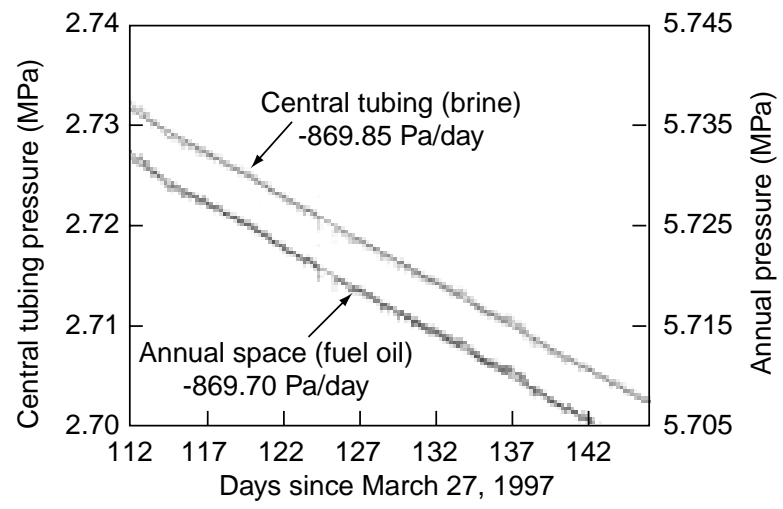

Figure 9

Annular space and central-tubing pressure drops. The two curves are almost parallel, a clear sign of no well leak. Small fluctuations are related to terrestrial tidal waves and groundtemperature variations. larger than fuel-oil density $\left(\rho_{f}=850 \mathrm{~kg} / \mathrm{m}^{3}\right)$. A fuel-oil leak yields to an upward vertical displacement of the fuel-oil/brine interface and, therefore, to an additional pressure drop in the central tubing, $\dot{P}_{t}=\dot{P}_{a}-\left(\rho_{b}-\rho_{f}\right) g Q_{t} / S$, where $S=21.1 \mathrm{l} / \mathrm{m}$ is the central tubing cross-section area.

A fuel-oil leak from the annular space acts in the reverse: the pressure drop rate in the tubing is simply $\dot{P}_{t}=\dot{P}_{i}-Q_{t} /(\beta V)$, and is $\dot{P}_{a}=\dot{P}_{t}-\left(\rho_{b}-\rho_{f}\right) g Q_{a} / \Sigma$ in the annular space whose cross-section is $\Sigma=5.7 \mathrm{l} / \mathrm{m}$. As a whole, when taking into account the cavern-volume loss rate:

$$
\begin{aligned}
& \left.\begin{array}{l}
\dot{P}_{a} \\
\dot{P}_{t}
\end{array}\right\}=\frac{V \dot{\varepsilon}_{\text {therm }}+V \dot{\varepsilon}_{\text {perm }}+Q_{a}+Q_{t}+V \dot{\varepsilon}_{\text {creep }}}{\beta V} \\
& -\left(\rho_{b}-\rho_{f}\right) g \cdot\left\{\begin{array}{l}
Q_{a} / \Sigma \\
Q_{t} / S
\end{array}\right.
\end{aligned}
$$




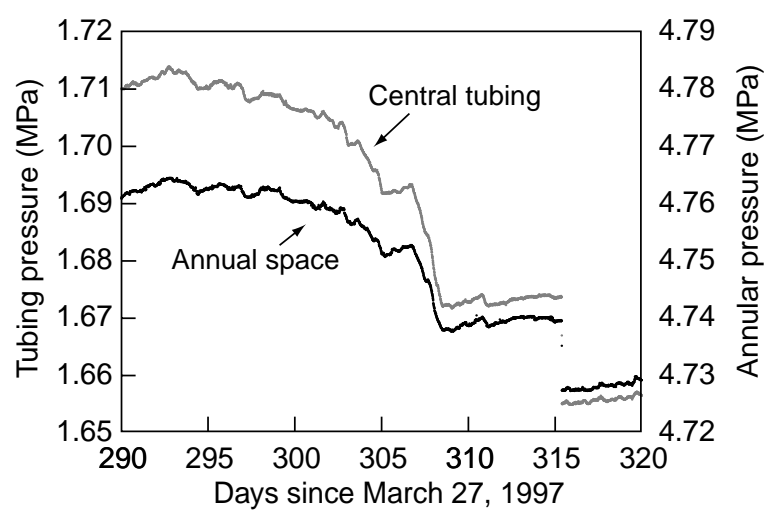

Figure 10

Annular space and tubing pressure during a well leak The two curves are parallel before day 293 and after day 315 .

Of course, when:

$Q_{a}=Q_{t}=0$ (no leak), then $\dot{P}_{a}=\dot{P}_{t}=\dot{\varepsilon}_{\text {perm }}+\dot{\varepsilon}_{\text {creep }} / \beta$, as explained above ( $V \dot{\varepsilon}_{\text {therm }}$ can be disregarded during the described test).

Figure 10 provides an example of annular-space and central-tubing pressure variations as measured through gauges with a resolution of $\pm 0.5 \mathrm{kPa}$ and plotted versus time. Between days 290 to 293 , the difference is fairly constant. In fact, there is a small negative difference $\left(\dot{P}_{a}-\dot{P}_{t}\right)$ of approximately $-60 \mathrm{~Pa} /$ day. On day 293 , a rapid and severe decrease of the pressure difference takes place - clear evidence of a fuel-oil leak through the central-tubing well head. The cumulated differential pressure from day 293 to day 314 is $\delta P_{a} \approx 21 \mathrm{kPa}$, which proves that the fuel-oil leak during this phase is $V_{a}=S \delta P_{a} / g\left(\rho_{b}-\rho_{f}\right)=21 / 0.17 \approx 1241$. The interface has risen by $V_{a} / S=6 \mathrm{~m}$ in the central tubing. On day 315 , the leak was repaired. (Note that the leak had been detected through curve observation before being observed in the field.) The pressure difference remained constant afterward.

In conclusion, this test proved that the fuel-oil test can be extremely accurate; when a nitrogen test (the more common test method) cannot be performed (e.g., when the well head is not able to withstand pressures such as those involved in a nitrogen leak test), the fuel-oil test is a good alternative. It is, however, probably less sensitive to tiny leaks.

\section{NITROGEN LEAK TEST: THEORETICAL ANALYSIS}

\subsection{Principle of the Test}

The Nitrogen Leak Test (NLT) is probably the most popular well-test method. Nitrogen is much less viscous than liquid, allowing very small leaks to be detected. In the NLT (Fig. 4), the cavern is filled with brine (stored products are withdrawn before the test) and prepressurised so that the test pressure can be reached after nitrogen is injected in the annular space. When the nitrogen/brine interface reaches mid-depth, a first interface logging is performed. Then, the interface is lowered to its final position, below the last casing shoe in the cavity neck, where the horizontal cross-section $(\Sigma)$ ranges from one to a few square meters. The advantage of such a location is that is allows the well and a significant part of the cavern neck to be tested together. One significant drawback is that the larger the $\Sigma$ cross-section, the smaller the resolution. A downhole temperature $\log$ is run at the beginning and at the end of the test period, which lasts a minimum of $72 \mathrm{~h}$. It is recommended that three interface measurements be performed: immediately after the nitrogen injection; $24 \mathrm{~h}$ later; and, last, at least $24 \mathrm{~h}$ after that.

The roughest ("naive") interpretation consists of measuring the interface depth variation, $\delta h$, during period $\delta t$. Taking into account the horizontal cross-sectional area at interface depth, the nitrogen seepage rate, $\dot{m} / \rho$, is assumed to be:

$$
\dot{m} / \rho=Q=\Sigma \delta h / \delta t
$$

A CH2M Hill Report (1995) suggests the following: “An example of interface resolution on sensitivity measurements is given in the following example. An interface is observed to move upward 3 feet in 20 days under near-equilibrium conditions (i.e., $0.15 \mathrm{ft} /$ day). The average borehole diameter across this interval is 8 feet (i.e., $50.27 \mathrm{ft}^{3} / \mathrm{ft}$ ). Therefore, the average nitrogen leak rate is calculated as:

$$
Q=A V=\left(50.27 \mathrm{ft}^{2}\right)(0.15 \mathrm{ft} / \text { day })=7.54 \mathrm{ft}^{3} / \text { day } "
$$

In this example, since interface-depth measurements have an accuracy of $15 \mathrm{~cm}$, the resolution of the method is $1.5 \mathrm{~m}^{3} /$ day. This relatively poor resolution is due to the large cross-sectional area, $\Sigma$, at interface depth.

This naive interpretation, however, suffers from a more fundamental flaw: it is assumed that the nitrogen leak is the only factor able to lead to interface displacement —an assumption that is misleading, as will be discussed later. A better interpretation consists of taking temperature and pressure variations into account:

$$
\frac{\delta m}{m}=\frac{\delta P}{P}+\frac{\delta V_{g}}{V_{g}}-\frac{\delta T}{T}
$$

where $\delta V_{g}=\Sigma \delta h$ is the gas-volume variation. Average brine and temperature variations can be measured through pressure-temperature logs, but the accuracy of these measurements is often not better than that for measuring volume.

One key question concerns the amount of leakage a cavern should be allowed. A clarifying point has been made by Crotogino (1995) in a report prepared for the SMRI that 
was based on company responses. Crotogino makes a distinction between the Minimum Detectable Leak Rate (the measurement-system resolution) and the Maximum Admissible Leak Rate. He suggests that the test be designed in such a way that the MDLR be one-third of the MALR. The proposed MALR is $=150 \mathrm{~kg} /$ day $\left(\right.$ or $270 \mathrm{~m}^{3}$ per year when pressure and temperature are, respectively, $17 \mathrm{MPa}$ and $300 \mathrm{~K}$ at cavern depth. Thiel (1993) suggested similar figures: “(...) $160 \mathrm{~m}^{3} /$ year (1000 bbl/year) maximum is a minimum acceptable test resolution.”

In the following paragraphs, we propose a theoretical analysis of the NLT method (Bérest et al., 1995) to prove the following:

- interface displacement is not simply related to the nitrogen-seepage volume, as is assumed in the naive interpretation;

- measurements of well-head pressures allow a better interpretation, allowing a distinction between nitrogenseepage effects and external-factor effects.

\subsection{Theoretical Analysis}

\subsubsection{Gas Equation of State}

Nitrogen pressure distribution in the annular-space column can be obtained easily through the equilibrium equation provided that gas pressure at the well head, $P_{g}(t)=P(z=0, t)$, the nitrogen state equation, $\rho=\rho(P, T)$, and the geothermal temperature distribution, $T=T(z)$, are known:

$$
d P / d z=\rho g
$$

where $z$ is the depth below ground level, $P$ is the nitrogen pressure, $g$ is the gravity acceleration, $\rho$ is the nitrogen density, and $P$ and $\rho$ are functions of $z$ and $t$.

As a first approximation, the nitrogen state equation can be written as $P=r \rho T$, where $T$ is the (absolute) geothermal temperature, $T=T_{o}+A z$. Then,

$$
\frac{\rho_{z}^{\prime}}{\rho}=\frac{P_{z}^{\prime}}{P}-\frac{T_{z}^{\prime}}{T}=\frac{1}{T}\left(\frac{g}{r}-A\right)
$$

Now, $g / r=3.3 \cdot 10^{-2}{ }^{\circ} \mathrm{C} / \mathrm{m}$, and the geothermal gradient is $\mathrm{A} \approx 3 \cdot 10^{-2}{ }^{\circ} \mathrm{C} / \mathrm{m}$. In other words, only a small error is introduced when assuming the gas density to be uniform along the well:

$$
\rho(z, t)=\chi P_{g}(t)
$$

where $P_{g}$ is the gas pressure measured at the well head. This assumption considerably simplifies further calculations; a more precise description of gas-pressure distribution in the well can easily be obtained using a computer (Brouard, 1998).

\subsubsection{Pressure Equilibrium}

Let $h$ be the interface depth. At the nitrogen/brine interface, the brine and nitrogen pressures, often referred to as the test pressure, $P_{\text {int }}$, are equal. Let $P_{b}$ be the brine pressure as measured at the well head in the central tubing:

$$
P_{b}(t)+\rho_{b} g h=P_{g}(t)+\rho g h=P_{\mathrm{int}}
$$

\subsubsection{Gas Mass}

Let $h_{o}$ be the interface depth at the beginning of the test (after the initial pressure build-up). $\Sigma$ is the annular cross-section at interface depth, and $V_{g}^{o}$ is the initial gas volume (when $\left.h=h_{o}\right)$. The gas mass contained in the well can be written as:

$$
m=\rho\left[V_{g}^{o}+\Sigma\left(h-h_{o}\right)\right]
$$

\subsubsection{External Factors}

Let $\dot{\varepsilon} V$ be the cavern-brine volume increase rate due to external factors. The cavern volume change caused by pressure build-up is $\beta V \dot{P}_{i}$, where $\beta$ is the cavern compressibility factor. Then, the interface displacement $(\dot{h}<0$ when the interface rises) is (see Paragraph 2.6.2):

$$
\Sigma \dot{h}=-Q_{b}=\left(\beta \dot{P}_{i}-\dot{\varepsilon}\right) V
$$

\subsubsection{Barometric Effect}

Equations (15) through (18) illustrate the relation between the nitrogen leak rate $(\dot{m}<0)$, the interface displacement rate $(\dot{h})$ and the relative brine-volume and cavern-volume change $(\dot{\varepsilon})$ due to external factors (e.g., brine thermal expansion):

$$
\frac{\dot{m}}{\Sigma \rho}=C \dot{h}+\chi \frac{V_{g}^{o}+\Sigma\left(h-h_{o}\right)}{(1+k g h) \rho \beta \Sigma} \dot{\varepsilon}
$$

where $C$, the barometric coefficient, is:

$$
C=1+\frac{\chi\left[V_{g}^{o}+\Sigma\left(h-h_{o}\right)\right]\left[\Sigma /(\beta V)+\left(\rho_{b}-\rho\right) g\right]}{(1+\chi g h) \rho \Sigma}
$$

It should be noticed that, even when there are no external factors influencing interface displacements, the apparent leak (or $\Sigma$ ) is not equal to the actual leak $(\dot{m} / \rho)$, in sharp contrast to what was (incorrectly) suggested by Formula (11).

The ratio between the actual leak and the apparent leak, or $C$, is larger than 1: a naive interpretation of the nitrogen leak test underestimates gas seepage. This effect can be explained simply. The interface rise increases the weight of the annularspace column (which, at the time, contains less gas and more brine), leading to a small increase in cavern volume. This causes the interface rise to be less than if the cavern and cavern brine were perfectly stiff bodies. This effect has been called "barometric", as it is similar to an effect observed in a mercury barometer; it is larger when the annular crosssection $(\Sigma)$ is small. It is also observed that, even when no gas seepage takes place $(\dot{m}=0)$, the nitrogen/brine interface moves due to the other phenomena listed above. 
For illustration, it is useful, here, to give some orders of magnitudes. Let $\chi=1.15 \mathrm{~kg} \mathrm{~m}{ }^{-3} \mathrm{MPa}^{-1}, \rho=200 \mathrm{~kg} \cdot \mathrm{m}^{-3}$, $\rho_{b}=1200 \mathrm{~kg} \cdot \mathrm{m}^{-3}, g=10 \mathrm{~m} \cdot \mathrm{s}^{-2}, h=1000 \mathrm{~m}$, and $=20.9 \mathrm{~m}^{3}$. There are no external effects, $\dot{\varepsilon}=0$, and the actual nitrogen leak is $\dot{m} / \rho=1 \mathrm{~m}^{3}$ per day. The cavern volume is $V=50$ $000 \mathrm{~m}^{3}$, and $\beta \mathrm{V}=20 \mathrm{~m}^{3} \mathrm{MPa}^{-1}$. The following two extreme cases must be distinguished.

- The nitrogen/brine interface is located in the cavern neck, where the cross-section is large - say, $\Sigma=5 \mathrm{~m}^{2}$. Then,

$$
C \approx 1+\frac{\chi V_{g}^{o}}{\rho \beta V}=1.06
$$

and the barometric effect is small. Conversely, the interface rise rate is $\dot{h} \approx 0.2 \mathrm{~m} /$ day -i.e., of the same order of magnitude as the interface measurement resolution. Only a relatively long test (10 days or more) will allow the actual leak to be estimated correctly.

- The nitrogen/brine interface is located a few meters below the last cemented casing shoe, where the annular crosssectional area is small $\left(e . g ., \Sigma=2 \cdot 10^{-2} \mathrm{~m}^{2}\right)$ Then,

$$
C \approx 1+\frac{\chi V_{g}^{o}\left(\rho_{b}-\rho\right) g}{\rho \Sigma}=1.6
$$

\subsubsection{Relations Between Pressure and Leak Rate}

For a simpler interpretation, we assume later on that the annular cross-section is constant from ground level to the interface location, $\Sigma=\mathrm{S}$, and $V_{g}^{o}=S h_{o}$.

It is now easy to link the nitrogen leak rate $(\dot{m})$, the cavern-brine volume changes $(\dot{\varepsilon})$ and the interface displacement rate $(\dot{h})$ to the brine $\left(\dot{P}_{b}\right)$ and nitrogen $\left(\dot{P}_{g}\right)$ pressure variations as observed at ground level:

$$
\left\{\begin{array}{c}
\dot{m}=\frac{\rho S}{g\left(\rho_{b}-\rho\right)}\left(\dot{P}_{g}-\dot{P}_{b}+h \rho_{b} g \frac{\dot{P}_{g}}{P_{g}}\right) \\
\dot{\varepsilon}=\frac{\beta P_{\text {int }}}{g\left(\rho_{b}-\rho\right) h_{o}}\left[(1-C)\left(\dot{P}_{g}-\dot{P}_{b}\right)+h\left(\rho_{b}-C \rho\right) g \frac{\dot{P}_{g}}{P_{g}}\right] \\
\dot{h}=\frac{1}{g\left(\rho_{b}-\rho\right)}\left(\dot{P}_{g}-\dot{P}_{b}+h \rho g \frac{\dot{P}_{g}}{P_{g}}\right)
\end{array}\right.
$$

where $P_{\text {int }}$ is the nitrogen/brine interface pressure.

It is reasonable to assume $\dot{m}<0$ (gas seepage). A small amount of gas can be produced in some salt formations, but a large production of gas (which would mix with the injected nitrogen gas) is unlikely. The following three domains in the $\left(\dot{P}_{g}, \dot{P}_{b}\right)$ plane can be distinguished (see Fig. 11).

- In this domain, the interface rises $(\dot{h}<0)$ and $\dot{\varepsilon}>0$. (Thermal expansion, or cavern creep, plays significant role.) Note that we can have $\dot{P}_{g}>0, \dot{P}_{b}>0$ or $\dot{P}_{b}>0, \dot{P}_{g}<$ 0 or $\dot{P}_{b}<0, \dot{P}_{g}<0$.

- In this domain, the interface rises $(\dot{h}<0)$, but $\dot{\varepsilon}<0$. (Factors such as transient creep or brine permeation to the rock mass play a significant role.) Here, $\dot{P}_{g}<0$ and $\dot{P}_{b}<0$.

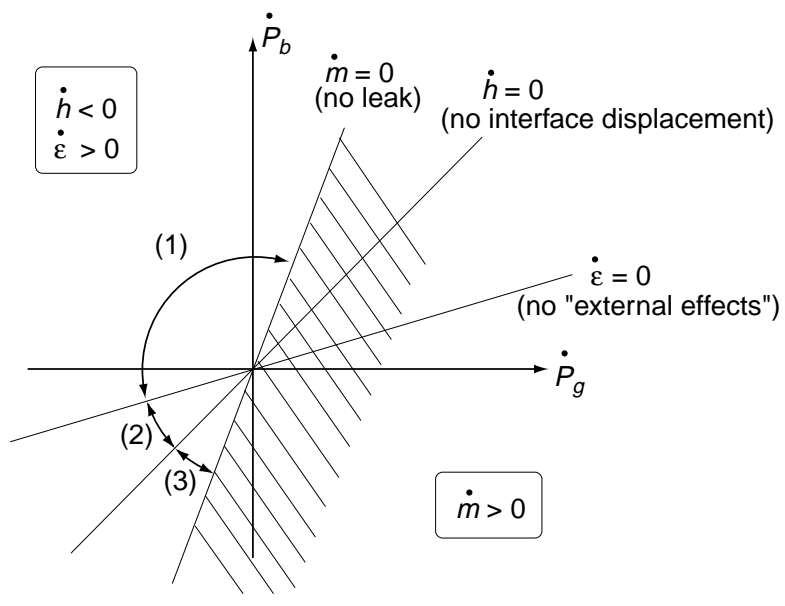

Figure 11

Different evolutions of well-head brine pressure $\left(\dot{P}_{b}\right)$ and gas pressure $\left(\dot{P}_{g}\right)$. Note that a nitrogen leak $(\dot{m}<0)$ can coexist with a nitrogen/brine interface drop $(\dot{h}>0)$.

- In this domain, the interface moves down $(\dot{h}>0)$ due to large transient creep or brine permeation even when gas seeps from the casing $(\dot{m}<0)$. This case highlights the erroneous conclusions that can be drawn from a naive interpretation.

\subsubsection{Accuracy}

It is relatively easy to measure gas and brine-pressure variations $\left(\delta P_{g}\right.$ and $\left.\delta P_{b}\right)$ with an accuracy of $1 \mathrm{kPa}$; the resulting accuracy on interface displacement is $0.2 \mathrm{~m}=20 \mathrm{~cm}$, which is similar to logging-tool accuracy $(2 \cdot 15 \mathrm{~cm}=30 \mathrm{~cm})$.

\section{NITROGEN LEAK TEST}

\subsection{Test Description}

In order to validate the theoretical analysis developed above, a nitrogen leak test was performed in March-April 1996 on the Ez53 cavern described above (Bérest et al., 1996). This $950 \mathrm{~m}$ deep, relatively small $\left(7500 \mathrm{~m}^{3} \pm 500 \mathrm{~m}^{3}\right)$ cavern had been leached out in 1982, 14 years before the test described below. Thermal equilibrium was believed to have been achieved in this cavern, based on a geothermal profile performed in February 1996. Furthermore, various tests, including the Fuel Leak Test described above (Bérest $e t$ al., 2001), had been performed in this cavern or in neighbouring wells (Hugout, 1988; Durup, 1994), providing a good knowledge of the various aspects of this cavern's behavior.

The objective of this test was not to verify the well tightness on the Ez53 cavern but, rather, to validate the test method. Test conditions were such that as zero leakage could 


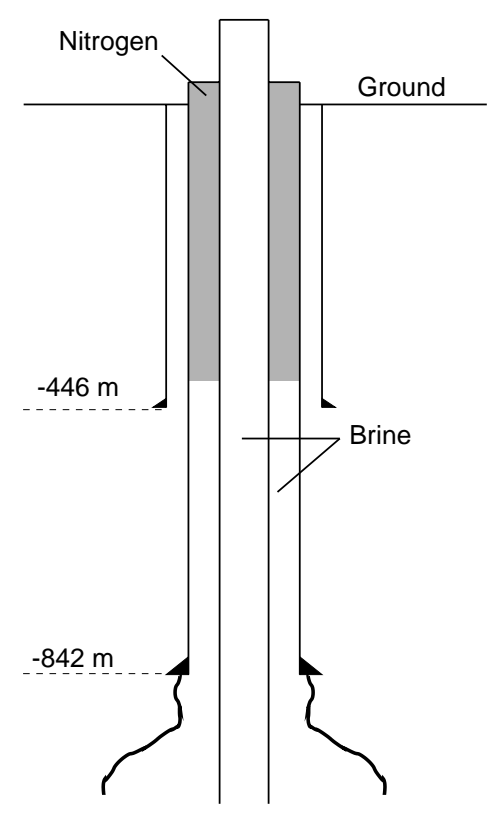

Figure 12

Test device for MIT performed on the Ez53 cavern.

be expected. The brine-nitrogen interface was lowered to the well's mid-depth (not to well bottom, as should have been done in an actual tightness test). At such a depth, gas is confined in the double-cased upper part of the well, where large amounts of seepage are very unlikely (see Fig. 12).

Artificial leaks were simulated by withdrawal or injection of calibrated amounts of brine or nitrogen through the well head. The concurrent pressure variations were measured at the well head, and interface displacements were tracked through a $(\gamma-\gamma)$ logging tool. Predicted interface displacement and pressure variations (using Equations (21)) were compared to measured values.

On February 29, 1996, the nitrogen/brine-interface depth was measured as $h=399.5 \mathrm{~m}$ using the $(\gamma-\gamma)$ logging tool. The well then remained idle until March 13. During this two-week period, gas pressure decreased from $7.57 \mathrm{MPa}$ to $7.30 \mathrm{MPa}$, and a tiny nitrogen leak from the annular space to the central tubing was suspected. (It is interesting to notice that no leak took place during the earlier 13-year period, when the annular space was filled with fuel oil, which is significantly more viscous than nitrogen.) It was decided to vent the nitrogen in the central tubing. This was done on March 13 and March 18. The nitrogen leak from the annular space to the tubing was estimated to be small and to have little influence during the tests.

$$
\left\{\begin{array}{l}
\chi=11.5 \mathrm{~kg} \cdot \mathrm{m}^{-3} \cdot \mathrm{MPa}^{-1} \quad h_{o} \approx 380 \mathrm{~m} \\
\rho_{b} \approx 1181 \mathrm{~kg} \cdot \mathrm{m}^{-3} \quad \rho_{g} \approx 86.5 \mathrm{~kg} \cdot \mathrm{m}^{-3}
\end{array}\right.
$$

Pressure and temperature profiles were measured on February 22 and March 18; they proved that well temperatures were identical for these two periods, $\dot{\varepsilon}_{\text {therm }}=0$.

The test properly began on March 20. Cavern pressure remained roughly constant during a one-month period before the test; it was hoped that this result in transient creep, transient permeation, and additional dissolution effects having negligible effects at the beginning of the test:

$$
\left(\dot{\varepsilon}_{\text {creep }}^{t}=\dot{\varepsilon}_{\text {dis }}^{t}=\dot{\varepsilon}_{\text {perm }}^{t}=0\right)
$$

On March 20, 1996, small amounts of brine or nitrogen were injected and withdrawn; the withdrawn or injected amounts of fluid were thoroughfully measured, and concurrent pressure variations were observed. Before and after each injection or withdrawal, the interface position was measured with the $(\gamma-\gamma)$ logging tool, which records the amount of electrons reflected by the fluid behind the steel central tubing. A sharp contrast between brine and nitrogen was expected. The sweeping rate of the tool was approximately $2 \mathrm{~m} / \mathrm{min}$, and a $10 \mathrm{~cm}$ resolution was expected. In fact, due to the small annular cross-section $\left(\Sigma=1.47 \cdot 10^{-2} \mathrm{~m}^{2}\right)$, tool accuracy proved to be poorer $(\delta h \approx 50 \mathrm{~cm})$.

\subsection{Test Results}

In order to simulate leaks, brine or nitrogen was injected and withdrawn at the well head. Brine volumes were measured through a flow meter with an accuracy of 0.51 ; nitrogen masses were computed by measuring the pressure and temperature in the nitrogen vessels before and after each injection or withdrawal of nitrogen. The exact nitrogen state equation (Air Liquide, 1997) was taken into account.

Table 1 provides information on the Nitrogen Leak Test at the Ez53 cavern: $h$ is the interface depth measured through the logging tool; $P_{b}$ and $P_{g}$ are brine pressure and gas pressure, as measured in the central tubing and in the annular space, respectively; and $\Delta V$ and $\Delta m$ are the injected (+) or withdrawn (-) amounts of brine or nitrogen.

\subsubsection{Barometric Effect}

The injections and withdrawals of nitrogen allow the so-called $C$ factor to be measured: the gas density is computed from the gas well-head pressure, $\rho=\chi P_{g}, \chi=11.5 \mathrm{~kg} \cdot \mathrm{m}^{-3} \cdot \mathrm{MPa}^{-1}$; the naive gas-seepage estimation (roughly deduced from interface displacement) is compared with the actual withdrawn nitrogen mass (Table 2). The $C$ factor, as computed from (20), is $C=1.9$ when the following figures are accepted (see Equation below).

The computed $C$ factor is in good agreement with the observed value (see Table 2).

$$
\begin{array}{rlrl}
V_{g} & \approx 6,8 \mathrm{~m}^{3} & \Sigma & \approx 1.47 \cdot 10^{-2} \mathrm{~m}^{2} \\
\beta V & \approx 2.92 \mathrm{~m}^{3} \cdot \mathrm{MPa}^{-1} & g & =9.81 \mathrm{~m} \cdot \mathrm{s}^{-2}
\end{array}
$$


TABLE 1

Measurements made during the Nitrogen Leak Test on Ez53

\begin{tabular}{|c|c|c|c|c|}
\hline & Brine injection & Brine withdrawal & Nitrogen injection & Nitrogen withdrawal \\
\hline$h$ before $(\mathrm{m} \pm 0.2)$ & 382.3 & 379.5 & 381.9 & 385.8 \\
\hline$h$ after $(\mathrm{m} \pm 0.2)$ & 379.5 & 381.9 & 385.8 & 382.1 \\
\hline$P_{b}$ before $(\mathrm{MPa} \pm 0.025)$ & 3.066 & 3.151 & 3.060 & 3.082 \\
\hline$P_{b}$ after $(\mathrm{MPa} \pm 0.025)$ & 3.133 & 3.084 & 3.082 & 3.065 \\
\hline$P_{g}$ before $(\mathrm{MPa} \pm 0.050)$ & 7.057 & 7.119 & 7.062 & 7.114 \\
\hline$P_{g}^{s}$ after $(\mathrm{MPa} \pm 0.050)$ & 7.095 & 7.084 & 7.116 & 7.065 \\
\hline$\Delta V(1 \pm 0.5)$ & +200.0 & -200.0 & 0 & 0 \\
\hline$\Delta m(\mathrm{~kg} \pm 0.1)$ & 0 & 0 & +9.20 & -8.09 \\
\hline
\end{tabular}

TABLE 2

Comparison between actual leak and apparent leak - Barometric effect

\begin{tabular}{l|c|c}
\hline & Nitrogen withdrawal & Nitrogen injection \\
\hline Nitrogen mass variation $\Delta m$ measured $(\mathrm{kg})$ & -8.09 & +9.20 \\
Average density $\rho_{g}\left(\mathrm{~kg} \cdot \mathrm{m}^{-3}\right)$ & 86.8 & 86.1 \\
"Naive" interface depth variation $\Delta h=\Delta m /\left(\Sigma \rho_{g}\right)(\mathrm{m})$ & -6.3 & +7.3 \\
Measured interface depth variation $(\mathrm{m})$ & -3.7 & +3.9 \\
As measured $C$ factor & $6.3 / 3.7=\mathbf{1 . 7}$ & $7.3 / 3.9=\mathbf{1 . 9}$ \\
\hline
\end{tabular}

TABLE 3

Comparison between computed and measured values

\begin{tabular}{l|c|c|c|c|c|c|c|c}
\hline & \multicolumn{2}{|c|}{ Brine injection } & \multicolumn{2}{c|}{ Brine withdrawal } & \multicolumn{2}{c}{ Nitrogen injection } & \multicolumn{2}{c}{ Nitrogen withdrawal } \\
\hline & Computed & Measured & Computed & Measured & Computed & Measured & Computed & Measured \\
\hline$\Delta P_{b}(\mathrm{kPa})$ & +60 & +67 & -60 & -67 & +19 & +22 & -17 & -17 \\
$\Delta P_{g}(\mathrm{kPa})$ & +34 & +38 & -35 & -35 & +56 & +54 & -49 & -49 \\
$\Delta h(\mathrm{~m})$ & -2.54 & $-2.8 \pm 0.2$ & +2.97 & $+2.4 \pm 0.2$ & +3.20 & $+3.9 \pm 0.2$ & -3.19 & $-3.7 \pm 0.2$ \\
$\Delta V(\mathrm{l})$ & +224 & $+200 \pm 0.5$ & -231 & $-200 \pm 0.5$ & +14 & 0 & -0.4 & 0 \\
$\Delta m(\mathrm{~kg})$ & -0.09 & 0 & +1.01 & 0 & +8.50 & $+9.20 \pm 0.1$ & -8.13 & $-8.09 \pm 0.1$ \\
\hline
\end{tabular}

\subsubsection{Prediction of Interface Displacement and Fluid Seepage Volumes}

Equations (21) allow to compute the interface displacements, the nitrogen-mass variations and the brine-volume variations when gas- and brine-pressure variations are known. Table 3 gives the computed and measured figures.

A reasonable agreement is met between as measured leaks and computed leaks, which proves that gas seepage rates and/or external effects rates can be correctly back-calculated from well-head pressure variations, provided these variations are accurately measured.

\subsection{Conclusions}

This test may be the first attempt to validate the Nitrogen Leak Test method. The following two main conclusions can be drawn.

- It is possible to detect relatively small brine or gas leaks (200 1 and $8 \mathrm{~kg}$, respectively) and to measure them with an accuracy of $\pm 20 \%$ through both the interface displacement and pressure-evolution measurements. This accuracy was achieved by locating the fluid-fluid interface in a relatively narrow part of the annular space. 
- Back calculation of interface displacement (when wellhead pressures evolution is used) requires precise mathematical formulations, but it supports (at very low cost) the results of the interface-displacement measurement obtained by using the logging tool.

\section{CONCLUSION}

Salt caverns provide one of the safest answers to the problem of storing large amounts of hydrocarbons. In most cases, from an engineering perspective, the salt formation itself can be considered as being perfectly tight. The real problem is the "piping" -i.e., the cemented well that links the cavern to ground surface. A correct well design (anchoring the last two cemented casings in the salt formation) prevents most later problems, but full-scale testing is necessary to build confidence in storage tightness. Several types of tests are available, and misinterpretation is possible, as real caverns are subject to various phenomena that can blur the significance of the observed evolution of a pressurised cavern during a test. We have attempted to prove that tests can be performed in such a way that a high degree of accuracy is achieved, leading to more confidence in test results. These methods could be applied in other fields of underground use when tightness is an important objective.

\section{ACKNOWLEDGEMENTS}

The test would not have been possible without dedicated help from Gaz de France Etrez staff and from École polytechnique staff (J. Bergues, Y. Le Bras, V. De Greef). The authors are also deeply indebted to K. Sikora.

\section{REFERENCES}

Air Liquide, Division scientifique (1997) Encyclopédie des gaz Gas Encyclopedia, Elsevier Ed.

ATG (1985) Manuel pour le transport et la distribution du gaz. Titre XIII, Stockages souterrains de gaz. Association technique de l'industrie du gaz en France, Paris.

Bérest, P., Brouard, B. and Durup, G. (1995) Some Comments on the MIT. Proc. SMRI Fall Meeting, San Antonio. (Proceedings of the "SMRI Meetings" are available at: SMRI-3336, Lone Hill Lane, Encinitas, CA 92024-7262, USA. These proceedings are edited as a separate volume since the Fall 1996 Meeting).

Bérest, P., Bergues, J., Brouard, B., Durup, G. and Guerber, B. (1996) A Tentative Evaluation of the MIT. Proc. SMRI Fall Meeting, Houston.

Bérest, P., Brouard, B., Beugin, F. and Goldberg, J. (1997) Storage of Tritiated Waters in Salt Caverns. Proc. SMRI Fall Meeting, El Paso, 49-63.

Bérest, P., Bergues, J. and Brouard, B. (1999). Review of Static and Dynamic Compressibility Issues Relating to Deep Underground Caverns. Int. J. Rock Mech. Sc., 36, 1031-1049.
Bérest, P., Brouard, B. and Durup, G. (2001) A Salt-Cavern Abandonment Test. Int. J. Rock Mech. Min. Sc., 38, 357-368.

Brasier, F.M. (1990) Assuring the Integrity of Solution Mining Operations, Proc. SMRI Fall Meeting, Paris.

Brouard, B. (1998) Sur le comportement des cavités salines Étude théorique et expérimentation in situ. Thèse de doctorat de l'École polytechnique, France.

Brouard, B.and Bérest, P. (1998) A Tentative Classification of Salts According to their Creep Properties. Proc. SMRI Spring Meeting, New Orleans, 18-38.

CH2M HILL, Inc (1995) Technical Manual for External Well Integrity TEsting Class III Salt Solution Mining Wells, Research Project Report No. 94-0003-S for The Solution Mining Research Institute.

Charpentier, J.P., Bérest, P. and Blum, P.A. (1999) Creep of a Rock Under Small Loading. Proc. SMRI Fall Meeting, Washington DC, 11-24.

Crotogino, F.R. (1995) SMRI Reference for External Well Mechanical Integrity Testing/Performance, Data Evaluation and Assessment. Summary of the Final Project Report, SMRI 95-0001.

Diamond, H.W. (1989) The Water-Brine Interface Method, an Alternative Mechanical Integrity Test for Salt Solution Mining Wells. Proc. SMRI Fall Meeting, San Antonio.

Diamond, H.W., Bertram, B.M., French, P.S., Petrick, G.D., Schumacher, M.J. and Smith, J.B. (1993) Detecting Very Small Casing Leaks Using the Water-Brine Interface Method, Proc. 7th Symp. on Salt, Kyoto, Elsevier Science, Amsterdam, 1, 363-368.

Durup, G. (1994) Long Term Tests for Tightness Evaluations with Brine and Gas in Salt. Proc. SMRI Spring Meeting, Houston.

Goin, K.L (1983) A Plan for Certification and Related Activities for Department of Energy - SPR Oil Caverns. SANDIA Report SAND 83-2005.

Heitman, N.A. (1987) Experience with Cavern Integrity Testing Using Nitrogen Gas. Proc. SMRI Spring Meeting, Tulsa.

Hugout, B. (1988) Mechanical Behavior of Salt Cavities -in situ Tests- Model for Calculating the Cavity Volume. Proc. 2nd Conf. Mech. Beh. of Salt, Hannover, Trans Tech. Pub., ClausthalZellerfeld, Germany, 291-310.

Hunsche, U. (1991) Volume Change and Energy Dissipation in Rock Salt During Triaxial Failure Tests. Collection Mechanics of creep brittle materials 2, ACF Cocks and ARS Ponter Ed., 172182.

Jordan, C.W. (1987) Cased Hole Logging for Determining Mechanical Integrity of Storage Wells. Proc. SMRI Spring Meeting, Tulsa.

Kelly, S.L. and Fleniken, J.A. (1999) The Development of Cement Evaluation Quality Control Measures for Cavern Wells. Proc. SMRI Spring Meeting, Las Vegas, 193-225.

Lindblöm, U.E., Jnedlid, I., and Forselles, T. (1977) Tightness Test of an Underground Cavern for LPG. Proc. 1st Int. Symp. Rock Store 77, Stockholm, 415-422.

Munson, D.E., De Vries, K.L., Fossum, A.F. and Callahan, G.D. (1996) Extension of the M-D Model for Treating Stress Drops in Salt. Proc. $3^{r d}$ Conf. Mech. Behaviour of Salt, Palaiseau, Trans Tech. Pub., Clausthal-Zellerfeld, Germany, 31-44.

Ratigan, J. (1991) Ground Subsidence at Mount Belvieu, Texas (Panel Discussion - Surface Subsidence). Proc. SMRI Spring Meeting, Atlanta.

Remizov, V.V., Pozdnyakov, A.G. and Igoshin, A.I. (2000) Examination of Rock Salt Underground Cavern Testing for LeakTightness by Pressure Alteration. Proc. SMRI Fall Meeting, San Antonio, 55-64. 
Rokahr, R.B., Hauck, R., Staudtmeister, K., and ZanderSchiebenhöfer, D. (2000) The Results of the Pressure Build-Up Test in the Brine Filled Cavern Etzel K102. Proc. SMRI Fall Meeting, San Antonio, 89-103.

Rummel, F., Benke, K. and Denzau, H. (1996) Hydraulic Fracturing Stress Measurements in the Krummhörn gas storage field, Northwestern Germany. Proc. SMRI Spring Meeting, Houston.

Thiel, W.R. (1993) Precision Methods for Testing the Integrity of Solution Mined Underground Storage Caverns. Proc. 7th Symp. on Salt, Elsevier Science Publisher, Amsterdam, 1, 377-383.

Thoms and Kiddoo (1998) SMRI Technical Class, in Guidelines for Safety Assessment of Salt Caverns, Roma.

Van Fossan, N.E. (1983) The characterization of Mechanical Integrity for Cased Boreholes Entering Solution Caverns. Proc. 6th Int. Symp. on Salt, Salt Institute, 2, 111-120.
Van Fossan, N.E. and Whelply, F.V. (1985) Nitrogen as a Testing Medium for Proving the Mechanical Integrity of Wells. Proc. SMRI Fall Meeting, Houston.

Van Sambeek, L.L. (1993) Evaluating Cavern Test and Surface Subsidence Using Simple Numerical Models. Proc. 7th Symp. on Salt, Kyoto, Elsevier Science, Amsterdam, 1, 433-439.

Veil, J., Elcock, D., Raivel, M., Caudle, D., Ayers, R.C. and Grunewald, B. (1997) Preliminary Technical and Legal Evaluation of Disposing of Nonhazardous oil Field Waste into Salt Caverns, Contract W-31-109-ENG-38, Argonne National Laboratory, US Department of Energy.

Vrakas, J.J. (1988) Cavern Integrity Testing on the SPR Program. Proc. SMRI Spring Meeting, Mobile.

Final manuscript received in september 2001 